\title{
LA RESILIENCIA DEL TERRITORIO AL CAMBIO CLIMÁTICO: RETOS Y HERRAMIENTAS JURÍDICAS DESDE EL PLANEAMIENTO URBANÍSTICO1
}

\section{TERRITORIAL RESILIENCE TO CLIMATE CHANGE: CHALLENGES AND LEGAL INSTRUMENTS FROM URBAN PLANNING}

\author{
JOSEP M. AGUIRRE I FONT \\ Profesor lector de derecho administrativo \\ Universitat de Girona \\ josepmaria.aguirre@udg.edu
}

Fecha de recepción: 31 de mayo de 2018 / Fecha de aceptación: 9 de septiembre de 2019

RESUMEN: Un nuevo reto recae sobre el urbanismo: la doble necesidad de frenar el cambio climático y, sobre todo, de hacer frente a los riesgos que este nos plantea mediante nuevos planeamientos resilientes. No se trata solo de planificar nuevos crecimientos capaces de resistir a las amenazas cada vez más reales del clima, sino de garantizar la conservación de los espacios más vulnerables, evitando que se vuelva a construir en ellos o incluso asegurando el derribo o traslado de las construcciones existentes. Este artículo se centra -a partir del análisis de experiencias previas en materia urbanística y de los instrumentos de adaptación de la costa en el derecho comparado- en analizar los límites y las posibilidades de la legislación urbanística para hacer frente a la adaptación al cambio climático, lo que plantea, en muchos casos, un problema jurídico complejo en torno a los derechos urbanísticos del propietario privado y un auténtico reto colectivo de futuro.

RESUM: Un nou repte recau sobre l'urbanisme: la doble necessitat de frenar el canvi climàtic i, sobretot, de fer front als riscos que aquest ens planteja mitjançant nous planejaments resilients. No es tracta només de planificar nous creixements capaços de resistir a les amenaces cada vegada més reals del clima, sinó de garantir la conservació dels espais més vulnerables, evitant que s'hi torni a

\footnotetext{
${ }^{1}$ Este artículo se ha redactado en el marco del proyecto "El urbanismo y sus instrumentos de incidencia positiva en el medio ambiente y en el cambio climático" (DER2017-85624-C3-1-R) dirigido por el Dr. Joan M. TRAYTER JIMÉNEZ y financiado por el Ministerio de Economía y Competitividad. Fue presentado en el I Congreso Catalán de Derecho ambiental (Tarragona, enero de 2018).
} 
construir o fins i tot assegurant l'enderrocament o trasllat de les construccions existents. Aquest article se centra - a partir de l'anàlisi d'experiències prèvies en matèria urbanística i dels instruments d'adaptació de la costa en el dret comparat- a analitzar els límits i les possibilitats de la legislació urbanística per fer front al canvi climàtic. Això planteja, en molts casos, un problema jurídic complex entorn dels drets urbanístics del propietari privat i un autèntic repte col-lectiu de futur.

ABSTRACT: Urban planning faces a new challenge: the double need to curb climate change and, more importantly, to cope with the risks posed by new resilient planning. It is not only about planning new growth capable of resisting the increasingly real threat of climate, it is also about guaranteeing conservation of the most vulnerable areas, avoiding new construction or even ensuring the demolition or relocation of existing buildings. This article focuses on analyses of previous experiences in urban planning and on the legal instruments to adapt the coast to comparative law. It analyses the limits and possibilities of urban planning legislation to address climate change. In many cases, this creates a complex legal problem regarding the urban development rights of private property owners and supposes a real collective challenge for the future.

PALABRAS CLAVE: Urbanismo - Ordenación del territorio - Medio ambiente - Adaptación al cambio climático - Mitigación - Responsabilidad patrimonial - Propiedad privada

PARAULES CLAU: Urbanisme - Ordenació del territori - Medi ambient Adaptació al canvi climàtic - Mitigació - Responsabilitat patrimonial Propietat privada

KEYWORDS: Urban planning — Land management - Environment - Climate change adaptation - Mitigation - Pecuniary responsibility — Private property

SUMARIO: I. Introducción: la problemática de articular instrumentos de planificación resilientes al cambio climático. 1. La planificación de los nuevos crecimientos resilientes a los cambios del clima. 2. La adaptación de los espacios transformados o planificados a los nuevos riesgos. II. Experiencias previas en la adaptación del planeamiento urbanístico al cambio climático en catalunya. 1. El desalojo del barrio de la Estació de Sallent (Bages) por problemas geológicos. 2. Las limitaciones en el desarrollo de la urbanización de Riumar en Deltebre (Baix Ebre) como consecuencia de la regresión litoral. 3. La articulación de un régimen transitorio en los planes directores urbanísticos del sistema costero para el traslado de los campings afectados por la regresión litoral. 4. Los problemas de las experiencias previas: la utilización impropia del sistema 
de espacios libres para mitigar el riesgo y la falta de instrumentos específicos para intervenir en el suelo transformado. III. El ejemplo de los instrumentos de adaptación de la costa al cambio climático en España, Portugal y Francia. 1. España: una estrategia que requiere del desarrollo de instrumentos urbanísticos autonómicos. 2. Portugal: una estrategia costera e instrumentos urbanísticos que incorporan la resiliencia del territorio al cambio climático. 3. Francia: el pionero Proyecto de Ley de adaptación de los territorios litorales al cambio climático. IV. Límites y posibilidades de la legislación urbanística para hacer frente al cambio climático. 1. Cómo revertir situaciones de riesgo sin repercutir los costes de la responsabilidad patrimonial en la administración pública. 2. Actuaciones urbanísticas para garantizar la resiliencia del planeamiento. a) Actuaciones de protección frente al riesgo. b) Actuaciones de acomodación frente al riesgo. c) Actuaciones de retroceso frente al riesgo. 3. Nuevos instrumentos para restituir los espacios transformados: la reparcelación forzosa o reversión de la reparcelación. V. Conclusiones. VI. Bibliografía.

\section{INTRODUCCIÓN: LA PROBLEMÁTICA DE ARTICULAR INSTRUMENTOS DE PLANIFICACIÓN RESILIENTES AL CAMBIO CLIMÁTICO}

El urbanismo se ha convertido en las últimas décadas en un instrumento esencial no solo para configurar el espacio en que vivimos sino también para garantizar una correcta aplicación de muchas otras políticas. Así, los instrumentos de planeamiento urbanístico o territorial son en la práctica el eje en que cristalizan las prescripciones de diversas políticas públicas, entre ellas las ambientales. ${ }^{2}$

El planeamiento debe ser capaz de identificar riesgos, adelantarse a los cambios y dar respuestas a muchos de los retos que tenemos planteados como sociedad. De todos ellos destaca un reto compartido con toda la humanidad, ${ }^{3}$ la doble necesidad de frenar el cambio climático $\mathrm{y}$, sobre todo, hacer frente a los riesgos que este nos plantea ya hoy. ${ }^{4}$

\footnotetext{
2 Sobre la importancia del planeamiento urbanístico y territorial desde la perspectiva ambiental se puede leer a Joan TRAYTER JIMÉNEZ, en Derecho Urbanístico de Cataluña, Atelier, Barcelona, 2016 (6a edición).

${ }^{3}$ Prueba de ello es la abundante literatura especializada desarrollada en la última década, y significativamente a partir de 2006, tras el huracán Katrina. Como pone de manifiesto Tapan K. DHAR and Luna KHIRFAN en "Climate change adaptation in the urban planning and design research: missing links and research agenda" publicado en Journal of Environmental Planning and Management, vol. 60, núm. 4, 2017.

${ }^{4}$ Los citados riesgos son puestos periódicamente de manifiesto por expertos a nivel mundial, en el marco del Grupo Intergubernamental de Expertos sobre el Cambio Climático (IPCC), pero también en Catalunya, gracias a las conclusiones de los informes "El cambio climático en Cataluña", elaborados por el CADS, el Institut d'Estudis Catalans, la Oficina Catalana del Cambio Climático y el Servicio Meteorológico de Catalunya, en colaboración con el Grupo de Expertos en Cambio Climático de Catalunya.
} 
En este contexto, y a falta de una legislación básica sobre la materia, se ha aprobado en Catalunya la Ley $16 / 2017$, de 1 de agosto, del cambio climático (LCC), ${ }^{5}$ que justamente tienen como objeto luchar contra los efectos del cambio climático desde la doble perspectiva clásica de mitigar y adaptar al cambio climático, pero también defendiendo el modelo de gobernanza de la administración en relación al cambio climático y estableciendo impuestos como instrumentos para actuar contra el cambio climático.

Desde la perspectiva urbanística, la LCC centra los esfuerzos en mitigar los efectos del cambio climático adoptando medidas encaminadas a un cambio de modelo urbanístico que priorice la rehabilitación del parque de viviendas y los edificios de consumo energético casi nulo y a reducir la vulnerabilidad y las emisiones de gases de efecto invernadero ${ }^{6}$-artículo 27 de la LCC.

En cambio, las previsiones urbanísticas de la LCC en relación a la adaptación al cambio climático son mucho más parcas. Se limitan a afirmar la necesidad de adaptar la normativa urbanística y ambiental para garantizar que los nuevos planeamientos urbanísticos y territoriales -así como sus modificaciones y revisiones- incorporen los impactos del cambio climático sobre el nuevo planeamiento, así como medidas para mitigarlo y adaptarse a él. ${ }^{7}$

\footnotetext{
${ }^{5}$ Contra la citada Ley se interpuso Recurso de inconstitucionalidad contra determinados de sus preceptos, al entender que los mismos invadían las competencias exclusivas del Estado en materia de bases y coordinación de la planificación general de la actividad económica (regla 13. ${ }^{a}$ ), bases de régimen minero y energético (regla 25.a ) y legislación básica sobre protección del medio ambiente. La interposición del recurso en noviembre de 2017 supuso la suspensión de la vigencia de muchos de estos preceptos hasta su levantamiento en marzo de 2018, que únicamente se mantuvo en relación a la prohibición del fracking.

6 Unos objetivos que vienen trabajándose desde hace años en el campo del urbanismo. Prueba de ello es el catálogo de propuestas dirigido por Ferran VALLESPINós y Domènec CUCURULL y titulado Mitigación y adaptación local al cambio climático, Diputació de Barcelona, Barcelona, 2008, o, más recientemente, el trabajo de Blanca ARELLANo RAmos y Josep Roca CLADERA titulado Planificación urbana y cambio climático, XLI Reunión de Estudios Regionales, Universitat Rovira i Virgili, Tarragona, 2015, o la obra colectiva dirigida por María Rosario ALONSO IBÁÑEZ titulada Retos del desarrollo urbano sostenible e integrado, Tirant lo Blanch, Valencia 2018.

7 Un reto que persiguen otros territorios y urbes a lo largo de la tierra. Como ejemplo de ellos, entre otros, el trabajo de Safira DE LA SALA sobre el planeamiento de la ciudad de São Paulo en "Considerações acerca da Política de Mudança do Clima no Município de São Paulo Lei $n^{\circ}$ 14.933 de 5 de Junho de 2009", Revista Brasileira de Ciências Ambientais, núm. 30, 2013. Pero también el artículo de Luis INARAJA VERA titulado "Ciudades y lucha contra el cambio climático: experiencias de municipios estadounidenses", Cuadernos de Derecho Local, núm. 56, Fundación Democracia y Gobierno Local, Barcelona, 2018; el trabajo colectivo dirigido por Gary GARDNER, Tom Prugh y Michael Renner Ciudades Sostenibles. Del sueño a la acción. La situación del Mundo 2016, Icaria Editorial, Barcelona, 2016, o, en relación específicamente al agua, el trabajo
} 
En términos similares, la Ley balear 10/2019, de 22 de febrero, de cambio climático y transición energética, o la Ley andaluza 8/2018, de 8 de octubre, de medidas frente al cambio climático y para la transición hacia un nuevo modelo energético en Andalucía, disponen la necesidad de operar modificaciones de la normativa y del planeamiento urbanístico para garantizar la adaptación al cambio climático, pero sin concretar mediante qué técnicas o herramientas.

Dichas obligaciones se suman a las exigencias de la Ley 21/2013, de 9 de diciembre, de evaluación ambiental, relativas a tener cuenta la mitigación y la adaptación al cambio climático en los procedimientos de evaluación de toda la planificación pública. ${ }^{8}$

Se trata de un mandato al legislador sectorial, urbanístico y ambiental para que articule instrumentos de planificación resilientes al clima, con capacidad para anticipar o absorber los efectos de un evento climático adverso de una forma oportuna y eficiente, para adaptarse o para recuperarse —un principio exigido en el artículo 2.c) de la misma LCC.

Pero la resiliencia tiene varias dimensiones. ${ }^{9}$ No se trata solo de planificar nuevos crecimientos capaces de resistir a las amenazas cada vez más reales del clima, sino que el planeamiento debe garantizar la conservación de los espacios más vulnerables, evitando que se vuelva a construir en ellos o incluso asegurando el derribo o traslado de las construcciones existentes, lo que plantea, en muchos casos, un problema jurídico complejo en torno a los derechos urbanísticos patrimonializados por el propietario privado. ${ }^{10}$

dirigido por Ángel MENÉNDEZ REXACH, Planificación y gestión del agua ante el cambio climático: experiencias comparadas y el caso de Madrid, La Ley, Madrid, 2012.

${ }^{8}$ Una previsión que, como reconoce el preámbulo de la Ley, no era obligatoria de acuerdo con las directivas europeas vigentes en aquel momento, pero que supuso un salto de escala en la introducción de las políticas en materia de cambio climático en la evaluación de toda la planificación pública.

9 Anthony FLINT, "Los derechos de propiedad y el cambio climático", Land Lines Magazine, Lincoln Institute of Land Policy, 2013.

10 Sobre la complejidad entre el derecho de propiedad y la articulación de un modelo de planificación urbanística para hacer frente al cambio climático ha reflexionado Sofía SIMOU en "La configuración filoclimática del derecho de propiedad", InDret. Revista para el Análisis del Derecho, núm. 3, Barcelona, 2017. 


\section{La planificación de los nuevos crecimientos resilientes a los cambios del clima}

En relación a los nuevos crecimientos, las soluciones para garantizar un planeamiento resiliente parecen a priori sencillas: se trata de planificar de forma cuidadosa a partir de los estudios de inundabilidad, riesgos geológicos o erosión de la costa, entre otros. ${ }^{11}$ Es decir, priorizando un modelo urbanístico que anteponga la rehabilitación del parque de viviendas a estos crecimientos y que impulse en cualquier caso los edificios de consumo energético casi nulo y con las menores emisiones posibles de gases de efecto invernadero.

De hecho, como afirma Alexandra Delgado-Jiménez, ${ }^{12}$ en la actualidad las principales estrategias para mitigar y adaptarse al cambio climático consisten justamente en priorizar la rehabilitación de las ciudades frente a nuevas extensiones, y aumentar asimismo la eficiencia energética del parque construido. Se trata de optimizar el tejido ya desarrollado, garantizando una mezcla de usos que evite desplazamientos al mismo tiempo que se avanza en una mejora de la eficiencia energética de los edificios.

Todas estas previsiones están ya contempladas en la legislación básica estatal en materia de suelo, que en la definición de desarrollo sostenible prioriza la rehabilitación de los edificios y la regeneración y renovación de los tejidos urbanos existentes. Dicha legislación prevé, asimismo, mantener en la situación de suelo rural aquel que tenga riesgos naturales -como los derivados del cambio climático-y que exige, en la evaluación ambiental, informes preceptivos y vinculantes de la administración hidrológica o de la administración de costas, esenciales a la hora de prevenir una parte de esos riesgos futuros -artículos 20 y 22 del Real Decreto Legislativo 7/2015, de 30 de octubre, por el que se aprueba el texto refundido de la Ley de Suelo y Rehabilitación Urbana (TRLSRU).

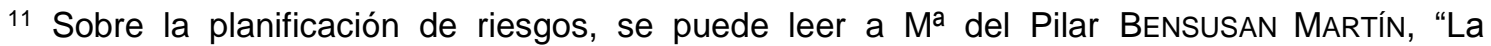
planificación como instrumento de prevención y gestión de los riesgos y desastres naturales", en la obra colectiva Retos del desarrollo urbano sostenible e integrado, dirigida por María Rosario ALONSO IBÁÑEZ, Tirant lo Blanch, Valencia, 2018 (p. 397-432).

12 Alexandra DeLGADO-JIMÉNEZ, "El impacto de las políticas climáticas en la legislación urbanística: una nueva agenda en relación con los usos del suelo y la energía", Políticas locales de clima y energía: teoría y práctica, Instituto Nacional de Administración Pública, Madrid, 2018 (p. 357-375).
} 
Disposiciones redactadas en términos similares están también incorporadas en la legislación urbanística autonómica ${ }^{13}$ que, con carácter general, prevé la necesidad de que el planeamiento preserve de la urbanización y la edificación las zonas de riesgo para la seguridad y el bienestar de las personas.

El análisis de los riesgos de los nuevos desarrollos se articula mediante el procedimiento de evaluación ambiental de planes y programas, que con la entrada en vigor de la Ley 21/2013, de 9 de diciembre, de evaluación ambiental, incorpora la mencionada exigencia de tener en cuenta la mitigación y la adaptación al cambio climático.

\section{La adaptación de los espacios transformados o planificados a los nuevos riesgos}

Pero, ¿qué sucede en relación a los espacios ya transformados o planificados? Aquí la legislación española es mucho más conservadora, evitando siempre asumir ningún coste económico o social, y desatendiendo, como consecuencia, la exposición a los eventuales riesgos derivados del cambio climático.

Buen ejemplo de ello es la última modificación del Reglamento del Dominio Público Hidráulico, operada por el Real Decreto 638/2016, de 9 de diciembre, que aunque limita y condiciona nuevas construcciones en la zona de flujo preferente - donde se pueden producir graves daños sobre las personas y los bienes - al final las admite siempre que el responsable conozca y asuma el riesgo. ${ }^{14}$

¿Es ajustada esta previsión desde la perspectiva del interés público y la obligación de la administración de velar por los principios rectores de la Constitución española, como el derecho a disfrutar de un medio ambiente

\footnotetext{
${ }^{13}$ Como ejemplo, en Catalunya, en materia de inundabilidad, las limitaciones se concretan en el artículo 9.2 del Decreto Legislativo 1/2010, de 3 de agosto, por el que se aprueba el Texto refundido de la Ley de urbanismo, que remite a las limitaciones de uso de la legislación sectorial. También en Catalunya, sobre riesgos geológicos, el artículo 5.2 del Decreto 305/2006, de 18 de julio, por el que se aprueba el Reglamento de la Ley de urbanismo, dispone que el planeamiento urbanístico, para la determinación de los riesgos naturales y geológicos, debe tener en cuenta la información geográfica oficial del Instituto Geológico de Catalunya.

${ }^{14}$ Mediante una declaración responsable por parte del promotor donde afirme conocer y asumir el riesgo, con la obligación de trasladarla a los afectados y la exigencia, en suelo urbanizado, de que el promotor disponga del certificado del Registro de la Propiedad en el que se acredite que existe anotación registral indicando que la construcción se encuentra en zona de flujo preferente.
} 
adecuado para el desarrollo de la persona o la propia protección de la salud? Es decir, ¿puede la administración tolerar la existencia de estas construcciones o, aún más, permitir que se sigan construyendo nuevas construcciones en estos espacios donde se ha acreditado un riesgo para personas y bienes? ¿Es suficiente la emisión de una declaración responsable por parte de un promotor o la anotación registral de esta realidad -como prevé la normativa de dominio público hidráulico - para que la administración se exima de eventuales responsabilidades?

$Y$ aunque sea suficiente, ¿es este el modelo deseable para afrontar los riesgos y retos que nos plantea el cambio climático, donde cada uno asuma individualmente esos riesgos?

El Anteproyecto de ley de cambio climático y transición energética, ${ }^{15}$ aprobado en febrero de 2019, aborda tímidamente estas cuestiones en un articulado que no aun ha llegado a tramitarse en el Congreso. En su artículo 16 propone elaborar, en colaboración entre el Estado y las comunidades autónomas, informes periódicos sobre la evolución de los impactos y riesgos derivados del cambio climático y sobre las políticas y medidas destinadas a aumentar la resiliencia y disminuir la vulnerabilidad. El Anteproyecto incorpora, en su artículo 19, la obligación de que la planificación y la gestión del desarrollo urbano, la edificación y las infraestructuras de transporte tengan en cuenta los riesgos del cambio climático, integren mecanismos de adaptación y resiliencia al cambio climático y calculen y diseñen las edificaciones e infraestructuras de transporte a los efectos derivados del mismo. Dichas obligaciones se proyectan sobre el planeamiento de ordenación del territorio y el urbanismo - mediante la modificación del artículo 20.1.c) del TRLSRU—, que deberá incorporar el principio de prevención de riesgos naturales y accidentes graves en la ordenación de los usos del suelo, entre ellos: riesgos derivados del mar; eventos meteorológicos extremos; riesgos de mortalidad y morbilidad derivados de las altas temperaturas; riesgos asociados a la pérdida de ecosistemas $\mathrm{y}$ biodiversidad, y riesgo de incendios.

${ }^{15}$ Texto consultable en el siguiente enlace: https://bit.ly/2E6kfag (última consulta, 14 de mayo de 2019). 
Sin perjuicio de que el citado anteproyecto devenga una realidad normativa, la perspectiva del cambio climático se va introduciendo en nuestra legislación sectorial, en materia de cambio climático o de evaluación ambiental, obligándonos a actualizar nuestro marco normativo para garantizar la resiliencia del planeamiento a los nuevos desafíos climáticos.

Ahora bien, como apunta Fernando López, 16 "está por ver la efectividad de este tipo de medidas, dando la impresión de que, solo cuando ocurra algún suceso grave, podrá chequearse su validez real. Y es que no parece que por el momento la adaptación al cambio climático se valore como un problema real y nuclear a la hora de elaborar el planeamiento urbanístico".

En este artículo analizaremos si la actual regulación se adecúa a este reto para garantizar la efectividad de los mecanismos de adaptación o si, por el contrario, deberían incorporarse nuevos instrumentos a la legislación para garantizarlo de forma efectiva. Centraremos la atención en el suelo ya clasificado o transformado, dado que, como ya se ha expuesto, el suelo no urbanizable plantea menos problemas en relación a su protección, pues la administración, mediante un uso adecuado de los instrumentos existentes, únicamente debe evitar su alteración.

Para hacerlo, observaremos experiencias urbanísticas previas en que la administración urbanística se ha visto obligada a resituar edificaciones 0 aprovechamientos en espacios en riesgo, y analizaremos a continuación las soluciones que España, Portugal y Francia han buscado para adaptar la costa a los efectos del cambio climático, pues, como veremos, muchas de las propuestas son trasladables a la legislación e instrumentos de planeamiento urbanístico.

\footnotetext{
16 Fernando LóPEZ PÉREZ, "La planificación urbanística municipal ante el cambio climático: expansión versus ciudad existente", Políticas locales de clima y energía: teoría y práctica, Instituto Nacional de Administración Pública, Madrid, 2018 (p. 377-403).
} 
El nuevo modelo obligará a mayor creatividad, innovación y nuevas formas de gobernanza, pero al mismo tiempo permitirá plantear escenarios más adaptativos a las características físicas de un espacio en evolución. ${ }^{17}$

\section{EXPERIENCIAS PREVIAS EN LA ADAPTACIÓN DEL PLANEAMIENTO URBANÍSTICO AL CAMBIO CLIMÁTICO EN CATALUNYA}

La progresiva incorporación a nuestra legislación de la obligación de adaptar el planeamiento al cambio climático, sumada a la exigencia de la legislación del suelo de preservar a las persones de los riesgos naturales -artículo 3.2.c) TRLSRU—, ha puesto a la administración urbanística en la tesitura de buscar soluciones a los riesgos naturales que ponen en peligro la vida de las personas y la permanencia de las edificaciones.

Como se ha expuesto anteriormente, la administración, por motivos de inundabilidad, mantiene una posición normalmente pasiva, pues la propia regulación sectorial admite la compatibilidad del riesgo con los usos y construcciones existentes. Influye en esta realidad, seguramente, el hecho de que los riesgos derivados de inundaciones son puntuales $y$, con las debidas medidas, controlables.

Existen sin embargo otros riesgos naturales a los que ha tenido que hacer frente la administración por el simple hecho de que sus consecuencias, lejos de ser temporales, son permanentes e imposibilitan físicamente la continuidad de los usos y construcciones afectados. Se trata de los derivados de problemas geológicos, cuando estos ponen en riesgo a las edificaciones, o de los usos y construcciones que se ven afectados por la erosión costera y el desplazamiento de la línea de dominio público marítimo-terrestre.

\footnotetext{
${ }^{17}$ Sobre los nuevos modelos de adaptación del urbanismo a las alteraciones climáticas, se puede leer a João Pedro Costa en Urbanismo e Adaptação às Alterações Climáticas. As frentes de agua, Livros Horizonte, Lisboa, 2013.
} 
Analicemos, a partir de tres ejemplos, las soluciones adoptadas por la administración urbanística en Catalunya para hacer frente a riesgos naturales sobrevenidos en sectores desarrollados o en desarrollo.

\section{El desalojo del barrio de la Estació de Sallent (Bages) por problemas geológicos}

Un ejemplo de ellos es el barrio de la Estació de Sallent (Bages). ${ }^{18}$ Se trata de un barrio residencial construido durante la década de 1960 sobre los límites de una antigua explotación minera llamada Enrique, que estuvo en funcionamiento entre 1932 y 1977. La mina cerró como consecuencia de filtraciones de agua provenientes del río Llobregat, que provocaron cavidades y disoluciones en el subsuelo. En 1997 este proceso de filtraciones llevó a la aparición de las primeras grietas en las viviendas del barrio, que empezaron a crecer a un ritmo de 2,5 cm anuales y llegaron a los $4 \mathrm{~cm}$ anuales en 2007. Por ello, en 2005, y como consecuencia de la anulación del planeamiento anterior, la Generalitat dictó unas normas urbanísticas de urgencia encaminadas a buscar una solución urbanística que necesariamente pasaba por el realojo de los habitantes.

La solución definitiva, en términos urbanísticos, llegó con el Plan de ordenación urbanística municipal de 2010, que abordó y gestionó los riesgos en el barrio de la Estació acordando el realojo de los vecinos —un proceso que ya se había iniciado-y el derribo de las construcciones existentes.

Para articularlo la Generalitat firmó convenios con los vecinos afectados, de tal forma que el realojo se pudiera llevar a cabo de forma consensuada y voluntaria. Con el objetivo final de que la totalidad del suelo del barrio fuera público y, después de proceder al derribo de las construcciones, destinarlo a zona de espacios libres. Por ello, se realojó a la población en un nuevo sector, desarrollado por la propia administración, que también asumió los importantes costes de la operación.

\footnotetext{
18 Sobre la transformación del barrio de la Estació de Sallent se puede leer a Cristina DOMĖNECH BERENGUER a "Transformació urbana del barri de l'estació (Sallent)" en Anuari Territorial de Catalunya, Societat Catalana d'Ordenació del Territori, Institut d'Estudis Catalans, Barcelona, 2005.
} 
El barrio de la Estació pasó a ser de titularidad pública, y con el derribo de las construcciones se convertiría en un sistema de espacios libres, con una regulación singular del resto, donde se admitieran usos de recreo y disfrute y la realización de actividades de carácter público, y también el empleo temporal para fiestas, espectáculos y ferias, siempre que no se causaran perjuicios, y de acuerdo con las condiciones que dictara el Ayuntamiento. Se prohibiría sobre estos suelos cualquier tipo de edificación y otros aprovechamientos del subsuelo, suelo y vuelo.

Las administraciones urbanísticas, Ayuntamiento y Generalitat, asumieron el coste de la operación de traslado y reconvirtieron el espacio en riesgo en espacios libres con capacidad para albergar actividades compatibles con los mismos. Pero pasada prácticamente una década de aquella operación el barrio de la Estació continúa siendo un gran solar cerrado al público, a la espera de un proyecto urbanístico que permita su transformación para recuperarlo para los nuevos usos.

\section{Las limitaciones en el desarrollo de la urbanización de Riumar en Deltebre (Baix Ebre) como consecuencia de la regresión litoral}

Un segundo ejemplo es la urbanización de Riumar en Deltebre (Baix Ebre). Se trata de un ámbito colindante con la playa, afectado por inundaciones y por la regresión del litoral que afecta al Delta del Ebro - muy castigado por una política hidrográfica que no permite la imprescindible aportación de sedimentos ${ }^{19}$ al río. En este ámbito, la aprobación del primer Plan Director Urbanístico del Sistema Costero $^{20}$ (PDUSC) en 2005 ya contempló una restricción drástica de la zona susceptible de nuevas edificaciones, protegiendo buena parte de los terrenos como consecuencia de su alto valor ambiental, al ser contiguos a un espacio natural protegido de la Red Natura 2000.

A pesar de las restricciones introducidas, en el marco de la tramitación del documento ambiental que acompañaba al plan parcial del sector se observaron

\footnotetext{
${ }^{19}$ Como pone de manifiesto el proyecto Life EBRO-ADMICLIM (ENV/ ES/001182), que plantea acciones piloto de mitigación y adaptación al cambio climático en el Delta del Ebro.

20 Sobre estos instrumentos se puede leer a Josep M. AGUIRRE I FONT en El régimen jurídico del litoral catalán, Atelier, Barcelona, 2014.
} 
-entre otros-riesgos por la posible inundación marina como consecuencia del cambio climático, que aconsejaban aumentar la cota de la urbanización un mínimo de 1,38 metros respecto a la actual y prohibir las construcciones a menos de 150 metros de la línea de costa actual. Como resultado de todo ello el plan fue informado desfavorablemente por parte del Departamento competente en materia de medio ambiente, una vez visto, entre otros, el informe de la Oficina del Cambio Climático.

Ello llevó al replanteo del documento, introduciendo en él importantes restricciones y prescripciones para proteger al sector de eventuales inundaciones marinas: aumento de la cota de urbanización; recomendación de construcción de una mota de protección alrededor de la zona a urbanizar; aportaciones anuales de arena, y supresión de la zona de equipamientos y zona de uso hotelero situadas en los primeros 200 metros de la línea de la costa. El plan parcial, aprobado definitivamente en 2014, dispone así que los primeros 100 metros de la franja litoral deberán dedicarse a espacios públicos libres, como ya se preveía, pero imposibilitando ubicar equipamientos en ellos, y los siguientes 100 metros, donde se proyectaba ubicar las construcciones hoteleras, deberán destinarse a espacios libres privados no edificables.

Se demuestra pues, con este ejemplo, que es posible proteger un ámbito previamente clasificado con la incorporación de nuevas prescripciones mediante el planeamiento derivado. Pero de nuevo se utiliza el recurso de los espacios libres - con independencia de la titularidad — para situar los ámbitos de mayor riesgo para edificaciones o personas.

\section{La articulación de un régimen transitorio en los planes directores urbanísticos del sistema costero para el traslado de los campings afectados por la regresión litoral}

El tercer y último ejemplo es la modificación que se introdujo en 2014 en los PDSUC. ${ }^{21}$ Los PDUSC disponían la posibilidad de que los campings en suelo no urbanizable existentes con anterioridad a los mismos pudieran seguir con su

${ }^{21}$ Edicto de 29 septiembre de 2014, sobre una resolución referente al Plan Director Urbanístico del Sistema Costero (PDUSC-1 y PDUSC-2), publicado en el DOGC de 29/09/2014. 
actividad limitando la posibilidad de ampliarlos. Primero la jurisprudencia del Tribunal Superior de Justicia de Catalunya, en la sentencia de 19 de junio de 2009 (recurso 79/2006), y después del Tribunal Supremo, en la sentencia de 20 de diciembre de 2012 (recurso 5454/2009), habían entendido dicha prohibición plenamente proporcional con los objetivos perseguidos por el PDUSC.

La proximidad al mar de una gran parte de los campings comportaba, pero, que se vieran en muchos casos afectados por los cambios producidos en el deslinde del dominio público marítimo terrestre, por la regresión de arenas o por el riesgo de inundabilidad por su proximidad a ríos y arroyos, unas alteraciones acentuadas por el cambio climático y por la modificación de la Ley de costas operada por la Ley $2 / 2013$, de 29 de mayo, que facilitaba el procedimiento de deslinde en los tramos en regresión.

La reducción del ámbito de los campings, como consecuencia de la legislación de costas, sumada a la limitación existente en los PDUSC de ampliar la actividad, conllevaba inevitablemente la reducción progresiva del negocio. Por ello la Generalitat optó por la modificación del régimen transitorio de los PDSUC, habilitando el traslado de unidades de acampada o edificios fuera de la superficie existente del camping, estableciendo, eso sí, que en los espacios naturales protegidos sería el Plan especial de protección del medio natural y del paisaje el Plan de ordenación de los recursos naturales, en la terminología de la legislación básica - la figura de planeamiento que regularía la ordenación de los usos y fijaría las normas de protección específicas en estos ámbitos.

Se trata de una habilitación concedida a la propiedad de la actividad para el traslado de la misma a suelos de idéntica protección, pues solo se amplía la actividad en la parte más alejada del mar. A diferencia de las soluciones analizadas anteriormente, aquí no entran directamente en juego los espacios libres, a pesar de que inevitablemente los espacios afectados por el deslinde, que dejarán de ser propiedad privada, pasarán a ser libres, públicos y gratuitos por imperativo de la Ley de costas. 


\section{Los límites de las experiencias previas: la utilización impropia del sistema de espacios libres para mitigar el riesgo y la falta de instrumentos específicos para intervenir en el suelo transformado}

Como puede apreciarse, los tres ejemplos se resuelven mediante soluciones diferentes, pero aplicando la normativa urbanística existente, sin instrumentos ad hoc, para dar solución a problemáticas singulares. En todos ellos, directa 0 indirectamente, interviene el sistema de espacios libres, en una concepción amplia que permite situar el riesgo o el ámbito en regresión sobre los mismos.

Como se aprecia en los ejemplos y ha puesto de manifiesto Martín Bassols, ${ }^{22}$ la adaptación al cambio climático no solo afecta al diseño, sino también, y muy especialmente, a la ejecución y la gestión por parte de las administraciones de esos espacios cuando ya se han transformado.

Ahora bien, la solución adoptada pone en cuestión la funcionalidad de estos espacios libres -parques, jardines, zonas verdes y espacios para el recreo, el ocio y el deporte-. Su exposición al riesgo puede limitar su uso y disfrute por parte de los ciudadanos de forma inmediata —como en el caso de Sallent-o en el futuro, con su desaparición efectiva como consecuencia, por ejemplo, del avance de la línea de costa.

También debe destacarse que las soluciones que permite la actual normativa son amplias en el momento de tramitación del plan, como demuestra el ejemplo del plan parcial de Deltebre, condicionado de forma importante por el documento ambiental, pero mucho más costosas y dificultosas cuando nos encontramos con ámbitos desarrollados como en Sallent, al vehicularse a través de mecanismos indemnizatorios, en los cuales la administración integró los costes.

Faltan, pues, probablemente, más y mejores instrumentos para garantizar una adaptación correcta de nuestro territorio a los nuevos riesgos derivados del cambio climático, sobre todo en los espacios ya transformados, unos instrumentos que planteen no solo la intervención mediante los espacios libres

22 Martín BASSOLS COMA, "La ejecución del planeamiento y el cambio climático", Políticas locales de clima y energía: teoría y práctica, Instituto Nacional de Administración Pública, Madrid, 2018 (p. 405-427). 
sino que también aborden el riesgo mediante la desclasificación del suelo, cuando sea necesario.

Se necesitan, por otra parte, soluciones adaptativas a un riesgo que también es evolutivo y cambiante; la planificación estática con que se ha articulado el urbanismo históricamente resulta ineficiente.

No se trata, pero, de un problema local, sino que ciertamente es un reto compartido con el conjunto de la humanidad, y es singularmente una prioridad vital en la franja costera, donde no solo se concentra la inmensa mayoría de la población, sino que es también donde los efectos del cambio climático, con el aumento del nivel del mar y la regresión de la línea costera, se verán con mayor rapidez.

Justamente por estos factores, los estados han priorizado la costa en la adaptación de su territorio al cambio climático, y nosotros analizaremos ahora las soluciones adoptadas por España, Francia y Portugal para intentar trasladarlas al resto de instrumentos urbanísticos.

\section{EL EJEMPLO DE LOS INSTRUMENTOS DE ADAPTACIÓN DE LA COSTA AL CAMBIO CLIMÁTICO EN ESPAÑA, PORTUGAL Y FRANCIA}

España, Francia y Portugal no solo comparten proximidad geográfica sino también instituciones y problemas muy similares. Los tres estados se plantean los problemas derivados del cambio climático, y singularmente en los espacios costeros más vulnerables por el incremento del nivel del mar y la erosión costera. Analicemos a continuación si los mecanismos articulados por la legislación costera de estos países pueden ser trasladables la legislación urbanística y aportar soluciones a las necesidades de adaptación del planeamiento al cambio climático.

1. España: una estrategia que requiere del desarrollo de instrumentos urbanísticos autonómicos 
En España la adaptación de la costa al cambio climático se articuló mediante la Ley $2 / 2013$, de 29 de mayo, de protección y uso sostenible del litoral y de modificación de la Ley 22/1988, de 28 de julio, de Costas. ${ }^{23}$

Se trata, como apuntó Ferran PONS, ${ }^{24}$ de una modificación legislativa tímida que incorporó al final de su tramitación algunas medidas de adaptación de la costa al cambio climático, centradas mayoritariamente en el ámbito del dominio público marítimo-terrestre, ignorando así la complejidad de gestionar los espacios colindantes. Ello obedece, con toda seguridad, a la distribución competencial en España, que otorga, como es conocido, las competencias urbanísticas y de ordenación territorial a la administración local y a las comunidades autónomas.

En la mencionada ley se introduce un régimen específico para los tramos de dominio público marítimo-terrestre en los que se verifique un retroceso. Sobre los mismos se dispone que no podrá otorgarse ningún nuevo título de ocupación del dominio público marítimo-terrestre. Aun así, las construcciones amparadas por un derecho de ocupación existentes en los terrenos declarados en situación de regresión grave se mantendrán, siempre que el mar no los alcance o no exista riesgo cierto de que lo haga.

Vinculada a este régimen, destaca la posibilidad de que en los terrenos declarados en situación de regresión grave la Administración del Estado pueda realizar actuaciones de protección, conservación o restauración, financiadas, en caso de que lo considere oportuno, mediante contribuciones especiales.

Justamente en la regulación de esas contribuciones especiales encontramos una previsión que se extiende, más allá del dominio público, a sus terrenos adyacentes,

\footnotetext{
${ }^{23}$ Muchas son las obras publicadas en relación con la reforma de la Ley de costas de 2013, pero sobre sus consecuencias en relación al cambio climático se puede leer a Belén NOGUERA DE LA MUELA en "La protecció del litoral a propòsit de la llei de protecció i ús sostenible del litoral de 2013 i el reglament de desenvolupament de 2014" dentro de El desenvolupament de l'autogovern en matèria de territori, paisatge, litoral i urbanisme, coordinada por Joan Manuel TRAYTER JIMÉNEZ y Carles García RocaSALVA, Institut d'Estudis Autonòmics, Barcelona, 2017 (p. 76-83).

${ }_{24}$ Ferran PONS CÁNOVAS, El nuevo régimen jurídico de las costas, Thomson-Reuters Aranzadi, Navarra, 2015. Sobre la regulación española de adaptación de la costa al cambio climático también se puede leer el artículo de Ferran PONS CÁNOVAS, "Resiliencia de la costa a los impactos del cambio climático después de la reforma de la normativa costera", Revista de derecho urbanístico y medio ambiente, núm. 329, 2019.
} 
pues se prevé la posibilidad de imponer contribuciones especiales ${ }^{25}$ cuando de la ejecución de las obras que se realicen en el dominio público marítimo-terrestre para su protección, defensa o mejora, o para la de los terrenos colindantes, resulte la obtención por personas físicas o jurídicas de un beneficio especial.

Otras medidas incorporadas en la reforma de la Ley de costas son la exigencia de que los proyectos para la ocupación del dominio público se acompañen de una evaluación de los posibles efectos del cambio climático, y la extinción de la concesión por la aparición del riesgo cierto de que las obras o instalaciones puedan ser alcanzadas por el mar.

Finalmente, la Ley impone al Ministerio de Agricultura, Alimentación y Medio Ambiente la obligación de elaborar una estrategia para la adaptación de la costa a los efectos del cambio climático —cuestionada por algunas comunidades autónomas, al entender que vulneraba sus competencias- ${ }^{26}$ Con ello se perseguía disponer de un diagnóstico riguroso de los riesgos asociados al cambio climático que afectan a nuestra costa y de una serie de medidas que permitan mitigarlos.

En cumplimiento de dicha obligación, la "Estrategia de adaptación al cambio climático de la costa española"27 fue aprobada con fecha 24 de julio de 2017 por la Dirección General de Sostenibilidad de la Costa y del Mar. ${ }^{28}$

En el documento, entre las diferentes medidas de adaptación, se priorizan aquellas que se caractericen por su robustez y flexibilidad, garantizando la adaptabilidad de las mismas a escenarios diversos e inciertos, así como las

\footnotetext{
25 Los sujetos pasivos de estas contribuciones especiales son quienes se beneficien de modo directo con las obras de protección, defensa y mejora del dominio público marítimo-terrestre, y especialmente los titulares de derechos de ocupación, así como los propietarios de las fincas y establecimientos colindantes. El mecanismo requiere su activación por parte del Gobierno mediante real decreto aprobado a propuesta de los Ministerios de Hacienda y Administraciones Públicas, y de Agricultura, Alimentación y Medio Ambiente.

${ }^{26}$ Sobre esta cuestión se pronunció el Tribunal Constitucional en la Sentencia 28/2016, de 18 de febrero de 2016, considerando plenamente constitucional la intervención del Estado en esta materia. 27 Sobre la misma se puede leer a Francisco-Javier SANZ LARRUGA en "Costas y litoral: biodiversidad marina, cambio climático y otras cuestiones", Observatorio de Políticas Ambientales 2016, coordinado por Fernando LÓPEZ RAMÓN, CIEMAT, Madrid, 2016 (p. 545-548), o al mismo autor en "Cambio climático y zonas costeras: aproximación a su ordenación jurídica y el papel de las administraciones locales", Políticas locales de clima y energía: teoría y práctica, Instituto Nacional de Administración Pública, Madrid, 2018 (p. 559-592).

${ }^{28} \mathrm{El}$ documento es consultable en el enlace https://goo.gl/JdnujK (última consulta, 24 de mayo de 2018).
} 
basadas en soluciones naturales 0 , subsidiariamente, las que cuenten con infraestructuras verdes.

Se trata de incorporar medidas que den respuesta a la imprevisibilidad, una agenda "What if?", ${ }^{29}$ al mismo tiempo que se priorizan soluciones naturales, en un enfoque más centrado en convivir con los cambios en lugar de evitar de cualquier forma las inundaciones. Una aproximación más similar al living with water, que los holandeses incorporaron en la década de los noventa, cuando tuvieron conciencia de los impactos que la política de mantener el agua fuera de su territorio -que históricamente habían desarrollado- producía en sus entornos y ciudades.

Partiendo de esas premisas, las opciones de adaptación - tal como veremos en otros ordenamientos- se clasifican en tres grandes grupos: protección, acomodación y retroceso. ${ }^{30}$ Las opciones de protección son las que permiten evitar los impactos; las de acomodación, las que priorizan la reducción de la vulnerabilidad de los espacios mediante la modificación de usos del suelo, y finalmente las opciones de retroceso se basan en el abandono planificado de las zonas susceptibles de verse afectadas por los impactos del cambio climático o por los riesgos extremos.

Entrando en el contenido concreto de las medidas, y centrando la atención en las de naturaleza urbanística y territorial, observamos cómo la estrategia propone adecuar funcional y estructuralmente las infraestructuras y edificaciones existentes para impedir o reducir los impactos de las inundaciones, y por ello propone introducir nuevos criterios en la normativa por parte de las entidades competentes.

También pone sobre la mesa la propuesta de realinear o hacer retroceder estructuras existentes, afirmando que el objetivo es poner en marcha proyectos

\footnotetext{
29 João Pedro Costa en Urbanismo e Adaptação às Alterações Climáticas. As frentes de agua, op. cit.

30 Una clasificación que deriva del Panel Intergubernamental sobre Cambio Climático de las Naciones Unidas, como pone de manifiesto el trabajo de Armando CARBONELL, Martin ZOGRAN y Dirk SIJMONS "Cambio climático, agua, urbanización de terrenos y adaptación: planificar desde la incertidumbre (Almare, Países Bajos)", en Urbanismo ecológico, Harvard University, Graduate School of Design, 2014.
} 
concretos de adaptación al cambio climático, pero sin concretar mediante qué mecanismos concretos se pueden desarrollar estas operaciones.

En la misma línea de falta de concreción, se propone la adquisición de terrenos en el dominio público marítimo-terrestre que pueden verse afectados por el cambio climático, condicionándola a su viabilidad legal y económica.

En paralelo, se propone trabajar con las administraciones competentes en fomentar cambios en los usos del suelo para reducir vulnerabilidad y riesgo al cambio climático, y la relocalización de actividades, infraestructuras y edificios. De nuevo, pero, sin ninguna otra precisión de cómo articularlo normativamente.

Las previsiones económicas, de calendario o las herramientas o instrumentos para facilitar las opciones de adaptación planteadas —algunas de ellas muy costosas en términos sociales, económicos o ambientales- son igualmente inconcretas. Todo ello da al documento un contenido muy poco ejecutivo y exige nuevamente su traslado a la legislación autonómica en materia de urbanismo, ordenación del territorio y ordenación del litoral. ${ }^{31}$

De hecho, esta es probablemente una de las principales diferencias con los otros ordenamientos que analizamos a continuación, en los que el Estado puede intervenir directamente, sin requerir de la adaptación posterior a las legislaciones de otros niveles administrativos.

\section{Portugal: una estrategia costera e instrumentos urbanísticos que incorporan la resiliencia del territorio al cambio climático}

En Portugal, el $75 \%$ de la población y el $85 \%$ del producto interior bruto se concentran en zona costera, y es también en este ámbito donde se aglutinan las principales áreas urbanas, industriales y turísticas, e importantes áreas naturales, rurales y de pesca. Todos estos elementos justifican la preocupación

\footnotetext{
${ }^{31}$ En este sentido, Judith GIFREU FONT en "La protección y utilización del demanio marítimoterrestre a propósito de la reciente jurisprudencia constitucional. Hacia una ordenación integrada y sostenible del litoral de Cataluña", Práctica Urbanística, núm. 140, Editorial Wolters Kluwer, 2016, defiende la necesidad de que las administraciones territoriales trabajen coordinadamente en la configuración de una planificación y gestión del litoral que permita prevenir los efectos de un desarrollo socioeconómico desproporcionado, y especialmente los efectos del cambio climático.
} 
del Estado portugués por abordar su gestión costera mediante un modelo a largo plazo.

En este contexto, en 2009 se aprobó la Estratégia Nacional para a Gestão Integrada da Zona Costeira (ENGIZC). ${ }^{32}$ A pesar de ello, los fuertes temporales que sufrió la costa portuguesa en el invierno de 2014 hicieron necesaria una actuación de urgencia y se replanteó la necesidad de hacer una reflexión más profunda sobre la gestión costera, lo que llevó a organizar un Grupo de Trabalho para o Litoral. $^{33}$ Los trabajos de este grupo se plasmaron en un documento titulado Gestão da Zona Costeira O Desafio da Mudança. Relatório do Grupo de Trabalho do Litoral, en diciembre del mismo 2014.

El documento concluye que la respuesta más adecuada a los desafíos derivados de las alteraciones climáticas pasaba por una adaptación de la costa en sentido amplio, no solo incluyendo la protección —que es la medida históricamente utilizada para protegerse de los temporales - sino también incorporando otras respuestas, como la relocalización de usos y edificaciones y la acomodación, con cambios de ocupaciones y actividades humanas y adaptación de infraestructuras. El documento apunta que las soluciones más eficaces resultan justamente de una combinación de las tres estrategias de adaptación, lo que permite una mayor sostenibilidad de las opciones en términos sociales, económicos y ambientales.

La estrategia de protección consiste en mantener, o incluso avanzar, la línea de costa por medio de la aportación artificial de sedimentos, de la construcción de dunas artificiales o de la construcción de estructuras como rompeolas o diques. La adaptación comporta incorporar cambios en la ocupación y actividades humanas en el litoral y la adaptación de las infraestructuras. La relocalización, según el documento, es una estrategia que implica la deslocalización de los usos y de la ocupación hacia el interior y que, en la práctica, se aplica generalmente cuando las otras estrategias se vuelven inviables, sobre todo en términos económicos.

32 Mediante la RCM n. 82/2009, de 8 de setiembre.

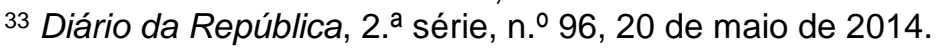


Todo ello debe articularse mediante un esfuerzo, por parte de instituciones públicas y privadas, de información, divulgación, educación y formación sobre la problemática de la zona costera, basadas en los principios de participación, prevención, precaución, desarrollo sostenible y gestión integrada de la zona costera.

En relación a la problemática de los espacios en riesgo que han sido clasificados o transformados, se propone prioritariamente la reubicación. Por ello, en primer lugar, la estrategia de relocalización debería evitar nuevas ocupaciones en estos espacios, sean urbanos o urbanizables. En paralelo, el documento propone, en el marco de la estrategia de relocalización, priorizar mecanismos de negociación que incluyan transferencia de edificabilidad de construcciones en zona de riesgo hacia zonas adecuadas, de conformidad con los municipios.

La previsión de transferencia de edificabilidad estaba recogida en la legislación portuguesa, en los instrumentos de gestión regulados en el Decreto Ley 380/99, ${ }^{34}$ como un mecanismo de compensación entre propietarios que estuvieran por encima o por debajo de la edificabilidad media de un ámbito sin recurrir a otras indemnizaciones.

Con la aprobación de la Ley $31 / 2014$, de 30 de mayo, de bases generales de la política pública de suelo, ${ }^{35}$ se amplían las posibilidades de autorizar las transferencias de edificabilidad en el planeamiento territorial, entre las que figuran, entre muchas otras, la prevención o minimización de riesgos colectivos inherentes a accidentes graves o catástrofes y de riesgos ambientales, que incluyen evidentemente los riesgos derivados del cambio climático.

Se trata de una Ley pionera, en este sentido, que incorpora como fines de la política pública de suelo, entre otros, ampliar la resiliencia del territorio a los efectos de fenómenos climáticos extremos o prevenir riesgos colectivos y reducir sus efectos sobre personas y bienes.

34 Diário da República n.ำ 222/1999, série I-A de 1999-09-22.

35 Diário da República n.․ 104/2014, série I de 2014-05-30. 
De los mecanismos para facilitar la adaptación del territorio al cambio climático, destaca también la previsión de un derecho de preferencia - derecho de tanteo-que habilita al Estado, a las regiones autónomas y a los entes locales a ejercerlo en las transmisiones onerosas entre particulares para, entre otros objetivos, prevenir o reducir los riesgos colectivos, entre los que figura el cambio climático.

En el esquema de planeamiento portugués, dividido entre programas y planes, las políticas públicas en materia de prevención de riesgos se articulan mediante los primeros, puesto que son los programas el instrumento mediante el cual se establece el marco estratégico de desarrollo territorial y sus directrices programáticas, sin perjuicio de que los programas vinculen a todo el esquema de planeamiento.

Estos programas, a su vez, son evaluados cada dos años por el Gobierno, mediante un informe sobre su aplicación que presenta a la Asamblea de la República, sin perjuicio de que la propia legislación portuguesa tiene mecanismos de seguimiento permanente y evaluación técnica de la eficiencia de la política de planificación y de los instrumentos que implemente. Se trata de elementos importantes, si tenemos en cuenta la rápida evolución de los efectos del cambio climático y de cómo se proyectan sobre el territorio.

En conjunto, todas estas propuestas representan una buena caja de herramientas que sin duda ayudará a la adaptación del planeamiento al cambio climático.

\section{Francia: el pionero Proyecto de Ley de adaptación de los territorios litorales al cambio climático}

Al igual que Portugal, Francia está desarrollado también nuevos instrumentos de adaptación al cambio climático centrando su atención en la costa, donde los efectos del mismo constituyen un problema especialmente grave, debido a los 19.200 quilómetros de litoral que tiene su territorio, una longitud que multiplica por más de dos la costa española, y que constituye un activo prioritario para el Estado francés, por su importancia turística, económica y patrimonial. 
Por ello, la Asamblea Nacional francesa ha vuelto a dar impulso a un Proyecto de Ley de adaptación de los territorios litorales al cambio climático, ${ }^{36}$ ya impulsado en la legislatura anterior, a pesar de no contar con el apoyo del actual Gobierno francés, que ha anunciado alternativas legislativas al Proyecto de Ley. El proyecto tiene como finalidad principal crear áreas de actividad temporal y flexible que permitan el mantenimiento de las actividades económicas y humanas, aunque transitoriamente, en lugares donde la línea de costa va en retroceso. ${ }^{37}$

La iniciativa parte de una cuestión fundamental: ¿cómo garantizar los derechos en zonas en riesgo por su inestabilidad? Para ello articula un conjunto de nuevas herramientas, para dar soluciones jurídicas a los propietarios de espacios que se encuentren en tramos en regresión. El debate se trasladó a la opinión pública francesa a partir de la problemática de un edificio de apartamentos en el municipio de Soulac-sur-Mer, evacuado en 2014 como consecuencia del avance del mar sin que los propietarios fueran compensados por ello.

El objetivo del Proyecto de Ley es dotar a las administraciones de herramientas legales para permitir a administraciones y actores privados gestionar los impactos derivados de la regresión de la línea litoral. Y estas soluciones deben posibilitar el mantenimiento de las actividades comerciales, inmobiliarias y humanas en las zonas con probabilidad de aparición de eventuales riesgos, hasta que se acredite la aparición efectiva de los mismos.

Para articularlas, el Proyecto crea la Stratégie nationale de gestion du trait de côte, elaborada por el Estado, y las Stratégies locales de gestion du trait de côte, elaboradas por las autoridades locales. Ambas estrategias, a sus respectivas

\footnotetext{
${ }^{36}$ La tramitación parlamentaria de la Proposition de loi $n^{\circ} 176$ (2016-2017) portant adaptation des territoires littoraux au changement climatique (consultable en el enlace https://goo.gl/Y28MaK; última consulta, 26 de abril de 2019) ha sido substituida en la XV legislatura - que empezó en setiembre de 2017- por la Proposition de loi relative au développement durable des territoires littoraux con un contenido muy similar (consultable en el enlace https://bit.ly/2rMeLxw; última consulta, 26 de abril de 2019).

${ }^{37}$ Sobre el Proyecto de Ley se puede leer a Jean-René MAXANT "La résilience des écosystèmes comme concept de gestion du littoral: les défis communs du traitement juridique des constructions et activités en zone à risques", Revista de Investigación Marina, núm. 25.2, Pasaia, 2018.
} 
escalas, quieren identificar los riesgos de la evolución de la costa y definir estrategias de gestión costera.

En relación a los daños producidos con anterioridad a la aprobación del Proyecto de Ley, se modifica el ámbito de aplicación del fondo de prevención de riesgos naturales, conocido como Fonds Barnier, para permitir que los afectados por desalojos de viviendas o actividades como consecuencia del riesgo derivado del retroceso de la línea de costa — con anterioridad a 1 de enero de 2017- sean indemnizados, sin tener en cuenta el riesgo de retroceso litoral, por un importe máximo de un $75 \%$ del valor estimado de cada inmueble. ${ }^{38}$

En relación a los eventuales riesgos futuros, el Proyecto define las llamadas Zones d'activité résiliente et temporaire (ZART), que servirán para adaptar la actividad a los riesgos existentes, a partir de las respectivas estrategias locales de gestión del litoral. En estas áreas se mantendrá la actividad humana y económica, ya sea agrícola, comercial, residencial o de servicios públicos, a pesar del riesgo de retroceso de la línea litoral, pero con límites jurídicos y temporales dentro de los cuales se podrán utilizar, explotar o trasladar edificios, obras, desarrollos o explotaciones.

Así, desde la perspectiva urbanística, se prevé que en las ZART la eventual reducción de su vulnerabilidad se pueda llevar a cabo mediante acciones u operaciones urbanísticas, pero también mediante el ejercicio de un derecho de preferencia - derecho de tanteo-o estableciendo reservas de suelos que se puedan llevar a término mediante expropiación.

En relación a estas operaciones, el Proyecto prevé que los Schéma de cohérence territoriale (SCOT), un instrumento de planeamiento supramunicipal, puedan definir los principios para reubicar actividades y propiedades incluidas en una ZART. Sobre su reubicación concreta, se dispone que el plan local de urbanismo pueda delimitar, fuera de las zonas próximas a la orilla, las zonas

\footnotetext{
38 Una propuesta, la Proposition de loi visant à instaurer un régime transitoire d'indemnisation pour les interdictions d'habitation résultant d'un risque de recul du trait de côte, que también ha sido recogida por otra proposición de Ley, impulsada en mayo de 2018 pero que tampoco cuenta con el apoyo del actual Gobierno francés, que ha anunciado un texto alternativo que aún no se ha presentado. La tramitación parlamentaria se puede seguir en el enlace https://www.senat.fr/dossier-legislatif/ppl17-307.html (última consulta, 26 de abril de 2019).
} 
destinadas a la relocalización de actividades y bienes afectados por una ZART. Estas reubicaciones no tienen que ubicarse necesariamente en continuidad a las aglomeraciones urbanas existentes - lo que constituye una excepción a un principio de la legislación urbanística francesa.

Desde la perspectiva de los derechos inmobiliarios, se regula el contrato de arrendamiento inmobiliario litoral, por el cual la administración pública autoriza a una arrendatario ubicado en una ZART a arrendar su inmueble bajo las condiciones fijadas en la propia Ley y mediante acta notarial. La duración de estos contratos, de entre 5 y 99 años, nunca podrá ser superior a los límites temporales fijados por la propia ZART para el desarrollo de actividades, sin que sea posible su renovación tácita.

Si el riesgo de avance del mar se materializa antes de la fecha de finalización del contrato, el arrendatario deberá abandonar el inmueble y las construcciones deben ser demolidas por el arrendador o por el arrendatario, en función de quien las realizase. Se prevé la posibilidad, incluso, de hipotecar el derecho real al arrendatario, pero con la previsión de confiscarlo si es necesario. Las eventuales pérdidas de arrendador y arrendatario como consecuencia de la finalización anticipada del contrato corren a su respectivo cargo. Asimismo, los profesionales inmobiliarios tienen la obligación legal de informar a sus posibles clientes propietarios, compradores, arrendadores o arrendatarios_ si una propiedad está situada en una ZART.

Finalmente, se regula el principio de indemnización y sus límites en relación a los inmuebles afectados por el retroceso de la línea de costa. Las indemnizaciones, igual que para las edificaciones afectadas con anterioridad a la entrada en vigor del Proyecto de Ley, se articulan a través del fondo para la prevención de grandes riesgos naturales, conocido como Fonds Barnier.

Las indemnizaciones —limitadas a un máximo del $75 \%$ del valor estimado de la propiedad - se pueden articular mediante dos vías. La primera, mediante expropiación, tan pronto como se pruebe menos costoso expropiar que construir protecciones mediante diques u otros elementos de la costa. Es la fórmula ordinaria mediante la cual se articula el Fonds Barnier. En estos casos se establece un límite 
temporal, pues los movimientos de tierra que justifiquen la expropiación deben presentarse antes del 1 de enero 2022 o una fecha anterior fijada por decreto. La segunda, una vez superada esta primera fase de indemnizaciones, las articulará siempre en el marco de las ZART, estableciendo diversas posibilidades a las que destinar los recursos - adquisiciones de bienes para desarrollar una operación urbanística que tenga como finalidad reducir la vulnerabilidad; limitación del acceso a estos bienes y su demolición posible, o compensación por pérdidas relacionadas con la realización anticipada del riesgo de retirada de la costa.

El Proyecto de Ley aporta un conjunto valioso de recursos urbanísticos y económicos para hacer frente a la necesaria adaptación del territorio al cambio climático. Se trata de unos instrumentos singulares que no solo intervienen en la esfera urbanística, sino que también lo hacen de forma significativa en la configuración del derecho de propiedad —limitando el valor de los inmuebles afectados y redefiniendo los derechos inmobiliarios de los mismos-, todo ello sumado a una importante aportación de recursos económicos que garantizarían, sin lugar a dudas, en caso de que el texto se apruebe, el éxito de los instrumentos planteados. Esta iniciativa debería servir de ejemplo para nuestro ordenamiento.

La aprobación del Proyecto de Ley, dada la oposición del actual Gobierno francés, es difícil con el actual redactado. A pesar de ello, los debates legislativos que se iniciaron hace tres años y las múltiples iniciativas legislativas a lo largo de este periodo — con hasta cuatro iniciativas similares—, dan fe de la importancia política de la materia en Francia y de la necesidad de una regulación específica.

\section{LÍMITES Y POSIBILIDADES DE LA LEGISLACIÓN URBANÍSTICA PARA HACER FRENTE AL CAMBIO CLIMÁTICO}

Como se ha analizado, existen en la legislación comparada instrumentos diversos para hacer frente a los riesgos del cambio climático, interviniendo singularmente sobre los espacios transformados. Pero, ¿qué sucede en el ámbito español? ¿Existen mecanismos suficientes en la legislación estatal y autonómica para intervenir sobre estos espacios si resulta necesario? 
Como hemos visto en las experiencias previas en Catalunya, las soluciones adoptadas hasta ahora son amplias en el momento de tramitación del planeamiento, pero que resultan mucho más costosas y dificultosas cuando nos encontramos con ámbitos ya desarrollados, donde la administración las articulaba mediante la adquisición de los mismos, previa cualificación como sistemas de espacios libres, y con mecanismos indemnizatorios donde la administración asumía la totalidad de los costes. Se trata de soluciones excepcionales que difícilmente pueden aplicarse con carácter general en los espacios en que aparezcan riesgos naturales sobrevenidos, pues la administración no puede operar como una aseguradora universal frente a los riesgos del cambio climático.

Por ello debemos preguntarnos ¿pueden las administraciones en España garantizar la resiliencia del planeamiento? y ¿qué costes deberá asumir para ello? Preguntas muy relevantes, si tenemos en cuenta la tradición urbanística española, donde en la práctica todos los costes se hacen pivotar sobre el propietario privado y los mecanismos en que la administración asume costes son muy poco utilizados.

Las claves a estas preguntas las encontramos, por una parte, en los instrumentos urbanísticos autonómicos, todos ellos similares y con raíces comunes, ${ }^{39}$ y por otra en la legislación estatal en materia de suelo, que regula los supuestos de responsabilidad patrimonial —pieza esencial para saber en qué casos la administración deberá asumir el coste de esas operaciones.

Estudiemos primero qué límites existen en la legislación estatal en materia de responsabilidad patrimonial para modificar los derechos de los propietarios $\sin$ asumir indemnizaciones que a día de hoy las administraciones consideran inviables. $Y$ a continuación analizaremos de qué instrumentos urbanísticos

\footnotetext{
${ }^{39}$ Esta diversidad permite multiplicar "las posibilidades de experimentación en lo que se refiere a enfoques y perspectivas y, sobre todo, en la puesta en práctica de las mismas", en relación a los instrumentos urbanísticos de adaptación al cambio climático, como pone de manifiesto la guía colectiva dirigida por Carlos VeRDAGUER VIANA-CÁRDENAS titulada Medidas para la mitigación y la adaptación al cambio climático en el planeamiento urbano. Guía metodológica, Federación Española de Municipios y Provincias, Madrid, 2015.
} 
disponemos en la legislación urbanística para garantizar la resiliencia del planeamiento y si es preciso revertir los espacios transformados.

\section{Cómo revertir situaciones de riesgo sin repercutir los costes de la responsabilidad patrimonial en la administración pública}

La actual legislación básica en materia de suelo plantea un sistema de responsabilidad patrimonial donde la administración debe indemnizar a los propietarios que - a pesar de haber patrimonializado su derecho cumpliendo con los deberes que les impone el planeamiento- vean limitados sus derechos a urbanizar y edificar. Se exceptúa así el principio general que habilita a la administración a planificar o modificar la ordenación territorial y urbanística sin necesidad de indemnización —artículo 4 del TRLSRU.

Ello conlleva que cualquier eventual modificación de planeamiento que plantee cambios en los derechos patrimonializados como consecuencia de su necesaria adaptación al cambio climático pueda llevar asociada la obligación de indemnización por parte de la administración.

Los supuestos, conocidos y ampliamente desarrollados por la doctrina, ${ }^{40}$ pueden ser -en relación a la problemática que nos ocupa- tres: modificaciones de planeamiento que impidan la ejecución de la urbanización; limitaciones singulares sobre construcciones y edificaciones que excedan de los deberes legalmente, y modificación o extinción de la eficacia de los títulos administrativos habilitantes de obras y actividades, también por cambios sobrevenidos en el planeamiento urbanístico.

Todos los supuestos requieren de los requisitos previos de responsabilidad patrimonial —daño efectivo, evaluable económicamente e individualizado con

\footnotetext{
40 Sobre los mismos, se puede leer a Jesús GonZÁLEZ PÉREZ en la obra titulada Comentarios a la Ley del suelo. Volumen II, Thomson-Civitas, Pamplona, 2015 (3a Aranguren y JUAN-Cruz Alli TURRILlas en la obra titulada Estudio sistemático del Texto refundido de la Ley del suelo. Real decreto legislativo 2/2008, de 20 de junio, Instituto Navarro de Administración Pública, Dykinson, Madrid, 2008; a José María BAÑo LEÓN, en la obra Derecho urbanístico común, lustel, Madrid, 2009; a Eva MENÉNDEZ SEBAStiÁn, Los supuestos indemnizatorios en la Ley 8/2007 de Suelo y en la legislación sobre espacios naturales, Thomson-Aranzadi, Navarra, 2007, y a Mariona LLEAL GRAU, "La responsabilidad patrimonial de la Administración Pública por alteración de la ordenación territorial y urbanística", Revista de Urbanismo y Edificación, núm. 19, 2009, Aranzadi, Navarra, 2010.
} 
relación a una persona o grupo de personas-, además de algunos requisitos adicionales en cada uno de los supuestos que abren algunas posibilidades que nosotros ahora describimos de forma superficial, al no ser el objeto central de este trabajo.

Así, la indemnización por alteración de las condiciones de ejecución de la urbanización exige que esta se produzca antes de transcurrir los plazos previstos para su desarrollo o, transcurridos estos, si la ejecución no se hubiere llevado a efecto por causas imputables a la administración.

La indemnización por eventuales vinculaciones y limitaciones singulares que excedan de los deberes legalmente establecidos respecto de construcciones y edificaciones, o conlleven una restricción de la edificabilidad o el uso, exige que esta no sea susceptible de distribución equitativa.

Finalmente, la modificación o extinción de la eficacia de los títulos administrativos habilitantes de obras y actividades, determinada por el cambio sobrevenido de la ordenación territorial o urbanística, exige que el daño sea efectivo y con ello se obligue al cese de la actividad o al derribo de la edificación. Así pues, las situaciones fuera de ordenación producidas por los cambios en la ordenación territorial o urbanística no serán indemnizables, sin perjuicio de que pueda serlo la imposibilidad de usar y disfrutar lícitamente de la construcción o edificación incursa en dicha situación durante su vida útil.

Esta regulación, pues, no comportaría indemnizaciones a las modificaciones de las condiciones de ejecución de la urbanización efectuadas una vez transcurridos los plazos previstos para su desarrollo. La aparición de responsabilidad, en este supuesto, exige: la aprobación previa del planeamiento derivado, su ejecución en el plazo previsto y la determinación el daño realmente existente mediante las inversiones y gastos efectuados. ${ }^{41}$ Ello otorga a la administración unas prerrogativas importantes de control, con posterioridad a la

\footnotetext{
${ }^{41}$ Así lo defiende el Tribunal Supremo en la sentencia de 12 de mayo de 1987 (RJ/1987/5255). En el caso concreto de Catalunya se exige, además, que los terrenos cuenten con la aprobación definitiva de los proyectos de urbanización y de reparcelación, cuando sea aplicable este sistema de actuación -artículo 115.2 del Decreto Legislativo 1/2010, de 3 de agosto, por el que se aprueba el Texto refundido de la Ley de urbanismo.
} 
aprobación del planeamiento general, en el momento de tramitar el instrumento de planeamiento derivado. Tal como sucedió en el citado ejemplo de Riumar, la administración puede incorporar, en esta fase del planeamiento, nuevas prescripciones necesarias para proteger a la población frente a los riesgos del cambio climático, con las consiguientes restricciones de los aprovechamientos, si es necesario.

Tampoco comportarían indemnización las eventuales vinculaciones y limitaciones singulares de construcciones y edificaciones si la legislación urbanística articula el mecanismo necesario para una distribución equitativa de dichas limitaciones. Esto permitiría, mediante la articulación de sectores discontinuos, compensar eventuales vinculaciones y limitaciones singulares en otros espacios más aptos para el desarrollo urbanístico, liberando así los espacios en riesgo y situando en ellos los espacios libres del sector discontinuo.

Finalmente, a pesar de que la modificación o extinción de la eficacia de los títulos administrativos habilitantes de obras y actividades conllevaría necesariamente indemnización por el cese de la actividad o el derribo, existen alternativas menos gravosas. Así, una eventual solución para evitar la responsabilidad sería situar las construcciones afectadas por el riesgo fuera de ordenación. De esta manera se limitaría el desarrollo del ámbito al mismo tiempo que se permitiría a los propietarios usar y disfrutar lícitamente de la construcción incursa en dicha situación durante su vida útil o hasta que el riesgo lo hiciera imposible.

Por lo tanto, en el marco de la legislación básica es posible desclasificar o imponer nuevas condiciones - sin asumir responsabilidad patrimonial- en sectores que no cuenten con planeamiento derivado o que no se haya ejecutado en el plazo dispuesto en el mismo, así como establecer limitaciones singulares en construcciones y edificaciones, siempre que sean susceptibles de distribución equitativa o bien permitan a los propietarios continuar usando y disfrutando lícitamente de sus construcciones durante la vida útil de las mismas -que inevitablemente se verá reducida por la aparición de los nuevos riesgos.

\section{Actuaciones urbanísticas para garantizar la resiliencia del planeamiento}


Sin perjuicio de los eventuales costes en materia de responsabilidad patrimonial, analicemos a continuación qué tipología de actuaciones urbanísticas pueden dar respuesta a la articulación de un planeamiento urbanístico resiliente al cambio climático.

De forma coherente con la clasificación adoptada a nivel internacional y utilizada, como hemos visto, por los instrumentos de adaptación a la costa al cambio climático, agrupamos las actuaciones en tres grupos: protección, acomodación y retroceso.

La aplicación de dichas actuaciones debe ser necesariamente progresiva, empezando por las actuaciones de protección, prosiguiendo por las de acomodación y dejando como último recurso las de retroceso.

Es oportuno apuntar, asimismo, que la escala adecuada de estas actuaciones - para garantizar su viabilidad y evitar los excesivos costes para la administración municipal - es la supralocal, con la necesaria participación de todos los niveles de poder territorial, como apunta Roberto O. Bustillo. ${ }^{42} \mathrm{La}$ solución de utilizar instrumentos de escala supralocal es también coherente con los instrumentos utilizados para la adaptación de la costa al cambio climático, como hemos visto. Lo contrario, hacer recaer la carga de adaptación de los espacios transformados en los municipios, sería muy poco realista.

La escala municipal, como defiende Avelino Blasco, ${ }^{43}$ es absolutamente insuficiente para albergar una planificación que tenga en cuenta las diversas perspectivas y políticas sectoriales. Pero es que, además, en términos de costes económicos y temporales, sería mucho más eficiente que una planificación de esta naturaleza se albergara en documentos estratégicos de escala territorial supralocal, liberando al plan urbanístico municipal local de resolver una

42 Roberto O. BUSTILLO BOLADO, "Integración y eficiencia de los recursos naturales en el ecosistema urbano", en la obra colectiva Retos del desarrollo urbano sostenible e integrado, dirigida por María Rosario ALONSO IBÁÑEZ, Tirant lo Blanch, Valencia, 2018 (p. 107-131).

${ }^{43}$ Avelino BLASCO ESTEVE, "La planificación territorial como factor decisivo del desarrollo territorial sostenible", en la obra colectiva Retos del desarrollo urbano sostenible e integrado, dirigida por María Rosario ALONSO IBÁÑEZ, Tirant lo Blanch, Valencia, 2018 (p. 237-254). 
problemática de esta dimensión —como defiende $M^{\underline{a}}{ }^{a}$ Mercedes Cuyás ${ }^{44}$ en relación a la planificación estratégica.

\section{a) Actuaciones de protección frente al riesgo}

En materia de actuaciones de protección —las dirigidas a evitar el riesgodebemos distinguir la tipología de suelo en relación a la que se aplican.

Así, en relación al suelo no urbanizable o rural que no debe transformarse, las obligaciones de protección frente al riesgo recaen sobre el propietario privado, por imperativo del artículo 16 del TRLSRU.

En relación al suelo sometido a una actuación de transformación, urbanizable o urbano no consolidado, las actuaciones de protección también forman parte de los deberes de los propietarios para patrimonializar el derecho a edificar. Así, en relación a este tipo de suelos, el planeamiento urbanístico - tal como vimos en el ejemplo de Riumar- puede establecer como cargas las determinaciones y obras que sean necesarias a los efectos de garantizar la seguridad del nuevo ámbito en desarrollo -artículo 18.1.c) TRLURU. Con un límite: la sostenibilidad económica de la actuación. Así, el artículo 22, apartados 4 y 5, de la TRLSRU exige que en las actuaciones "se asegure su viabilidad económica, en términos de rentabilidad, de adecuación a los límites del deber legal de conservación y de un adecuado equilibrio entre los beneficios y las cargas derivados de la misma".

Mucho más problemáticas son las actuaciones de protección en suelo urbano consolidado fuera del ámbito de una actuación de transformación urbana. Como hemos podido comprobar al inicio de este trabajo, la administración, con carácter general, aplica un criterio de tolerancia evitando los costes económicos o sociales de revertir determinadas situaciones - como los riesgos derivados de inundabilidades.

Existen, a pesar de ello, soluciones. Sea mediante la asunción de estos costes directamente por parte de la administración, o revertiendo una parte de ellos a

\footnotetext{
${ }^{44}$ Ma Mercedes CUYÁs PALAZÓN, "Los retos de la planificación estratégica", en la obra colectiva Retos del desarrollo urbano sostenible e integrado, dirigida por María Rosario ALONSO IBÁÑEZ, Tirant lo Blanch, Valencia, 2018 (p. 133-157).
} 
los beneficiarios de las obras o infraestructuras de protección mediante contribuciones especiales — de forma análoga a la previsión de la última reforma de la Ley de costas.

Una correcta aplicación de las actuaciones de protección evita desarrollar ámbitos sin las adecuadas obras o infraestructuras de urbanización para prevenir el riesgo. Pero, ¿qué sucede en relación a los suelos urbanos consolidados donde las citadas obras resulten técnicamente o económicamente inviables? Pues que debemos recurrir necesariamente a las siguientes actuaciones de acomodación.

\section{b) Actuaciones de acomodación frente al riesgo}

Las actuaciones de acomodación —donde se persigue la reducción de la vulnerabilidad del suelo mediante la modificación de usos del mismo- son esencialmente de aplicación al suelo urbano consolidado, pues en las otras tipologías de suelo una aplicación correcta de las actuaciones de protección evitaría su uso.

Así, en relación al suelo urbano consolidado, una opción ante la aparición sobrevenida del riesgo - que no pueda ser resuelta mediante obras de protección- es la modificación de los usos del mismo, declarando el cese de aquellos usos que se declaren incompatibles por el mayor riesgo para las personas o los bienes. Es una opción viable en términos urbanísticos, pero que exige indemnizaciones en relación a la modificación o extinción de la eficacia de los títulos administrativos habilitantes de obras y actividades.

Alternativamente el planeamiento puede modificar los usos de nueva implantación dejando los existentes en una situación transitoria o de fuera de ordenación, que permita usar y disfrutar lícitamente de la construcción o edificación incursa en dicha situación durante su vida útil.

Naturalmente, la elección de una u otra solución depende en buena parte de la inmediatez del riesgo. En este sentido, parecería una buena solución la configuración de mecanismos transitorios - similares a los estudiados en la legislación francesa- donde el planeamiento pudiera ir adaptando los usos y 
obras admitidos en función de la materialización del riesgo, con modulación, asimismo -mediante modificación de la legislación básica一, de los derechos inmobiliarios de las propiedades preexistentes. Se articularía, de esta manera, un régimen análogo a los usos y obras provisionales para futuras construcciones en estos espacios condicionados por el riesgo, que habilitaría a la administración a exigir su cese ante la aparición efectiva del riesgo. En el marco de estos mecanismos, la administración siempre podría recurrir al desalojo o cese de actividades con carácter de urgencia ante un escenario sobrevenido de riesgo, sin necesidad de indemnizar por ello.

Aun así, las actuaciones de acomodación no resultarán suficientes para dar una respuesta urbanística efectiva a las construcciones o actividades que por aparición del riesgo efectivo ya no puedan permanecer en ese espacio. Se requiere, en estos casos, recurrir a la última tipología de actuaciones, las de retroceso.

\section{c) Actuaciones de retroceso frente al riesgo}

Las actuaciones de retroceso son la última alternativa de la administración cuando las actuaciones de protección y acomodación han resultado inviables o insuficientes frente al riesgo. En ellas la administración opta por revertir el espacio transformado, sea para devolverlo a la situación original de suelo rural o para incorporarlo como parte del sistema de espacios libres - como hemos visto en el ejemplo de Sallent.

Naturalmente, para utilizar las actuaciones de retroceso la administración tiene múltiples instrumentos: expropiar, adquirir, resituar el aprovechamiento mediante alguna actuación que permita redistribuir beneficios y cargas, o bien obligando al propietario a ello.

Las más simples, desde la perspectiva de la gestión, son también las más caras desde la perspectiva económica, aquellas en que la administración expropia o adquiere asumiendo la totalidad del suelo afectado por el riesgo.

Mucho más complejas, pero también interesantes e innovadoras, son las actuaciones que permitan resituar el aprovechamiento mediante alguna 
actuación susceptible de distribución equitativa de beneficios y cargas entre los propietarios afectados.

Aquí distinguiríamos dos técnicas, la definición de sectores discontinuos y la transferencia de aprovechamiento urbanístico. En relación a la primera, la definición de sectores discontinuos permitiría al planificador situar los espacios libres del sector sobre el ámbito de riesgo y trasladar el aprovechamiento al otro sector sin riesgo —-dentro de la misma actuación y con proximidad a aquel—. Este recurso, utilizado anteriormente, tiene como principal problema que la administración debe asumir el coste de mantenimiento de un espacio de riesgo, que al mismo tiempo pierde parte de su funcionalidad —al alejarse del espacio al que presta servicio o, sencillamente, porque el riesgo imposibilita su goce y disfrute.

Alternativamente, en los ordenamientos autonómicos en que sea posible, se podría utilizar en términos similares la transferencia de aprovechamiento urbanístico. ${ }^{45}$ Esta técnica permitiría, previo acuerdo entre administración y propietarios, la adquisición por parte de la primera del sector en riesgo — sin coste alguno- y a cambio el propietario podría materializar el aprovechamiento del terreno cedido en una parcela distinta, donde lo sumaría al aprovechamiento propio de esa segunda parcela — hasta la edificabilidad máxima permitida por la norma- Este mecanismo tiene los inconvenientes de la primera técnica, con la dificultad añadida de que aquí se requiere el acuerdo previo y la existencia de una finca donde materializar el aprovechamiento. Por otra parte, la utilización de este mecanismo, que permite desvincular absolutamente la parcela original de la que obtiene el aprovechamiento, rompe con la concepción clásica del urbanismo que, como función pública, exige que el uso del territorio y del suelo en cada ámbito sea conforme al interés general de acuerdo con sus necesidades -lo que a priori tendría que impedir no solo trasladar aprovechamientos para

\footnotetext{
45 Sobre la transferencia de edificabilidad, se puede leer a Yásser-Harbi MUSTAFÁ TOMÁS en "Régimen de las transferencias y reservas de aprovechamiento urbanístico. En especial, el régimen de la Comunidad Valenciana", Revista de Derecho Urbanístico y Medio Ambiente, núm. 252, 2009. También a Laura I. FRANCIA ACUÑA, en "Las transferencias de aprovechamiento urbanístico como mecanismo de gestión para la obtención gratuita de suelos dotacionales y para compensar déficits de áreas verdes", en Revista de Derecho Urbanístico y Medio Ambiente, núm. 297, 2015, así como a Juli ESTEBAN I NOGUERA, L'ordenació urbanística: conceptes, eines $i$ pràctiques, Col-lecció Estudis, Diputació de Barcelona, 2007 (2ª edición).
} 
resolver problemáticas desvinculadas del sector o ámbito en cuestión, sino también desvincular los sistemas de las fincas a las que prestan servicios.

Existe, sin embargo, una tercera vía: la posibilidad de que la administración imponga la reversión de los suelos transformados, total o parcialmente, a la situación original de suelo rústico a sus propietarios. Ello evitaría a la administración asumir la gestión de los espacios libres en riesgo —pues estos permanecerían en la esfera privada - así como hacer un uso impropio del sistema de espacios libres.

Naturalmente esta vía exige, con carácter previo, que o bien los propietarios no hayan asumido sus obligaciones, con lo cual la administración se encuentra legitimada para revertir la situación, o bien asumir los importantes costes en términos de responsabilidad patrimonial que comportaría una operación de esta naturaleza.

En cualquier caso, y sin perjuicio de la eventual responsabilidad patrimonial, ¿pueden revertirse estas situaciones de riesgo devolviendo los suelos a su condición original de suelo rural y sin que la administración tenga que adquirirlos o expropiarlos?

\section{Nuevos instrumentos para restituir los espacios transformados: la reparcelación forzosa o reversión de la reparcelación}

La técnica urbanística, en España, se ha desarrollado históricamente sobre la premisa de articular instrumentos que permitieran la transformación y el desarrollo urbanístico del suelo rústico —que no deba ser preservado- o bien la rehabilitación del ya transformado. El proceso de transformación urbanística es pues unidireccional. No se ha planteado hasta ahora, de una forma bien articulada, la posibilidad de revertir los procesos de transformación urbanística legalmente implantados que, por motivos sobrevenidos, sea necesario devolver a suelo rústico.

Ciertamente, como consecuencia de la crisis, comunidades como Valencia o Castilla-La Mancha utilizaron mecanismos de reparcelación inversa o desreparcelación que permitieran desprogramar terrenos con desarrollos no 
finalizados, cuando los propietarios habían incumplido los deberes que les correspondían. Estos procedimientos se articularon mediante un proyecto de reparcelación forzosa, previsto en la legislación de estas comunidades, que permitía revertir la realidad alterada devolviendo las fincas, jurídica y físicamente, a su situación original.

El mecanismo de la reparcelación forzosa, pero, no había sido concebido para ello y planteaba numerosas dudas. Sobre todo, en materia de indemnizaciones, en relación a terceros de buena fe o sobre los eventuales derechos reales inscritos en el registro de la propiedad que no fueran compatibles con el suelo rural de las fincas de origen.

En este contexto algunas comunidades, como Andalucía, Valencia o Catalunya han empezado a articular jurídicamente estos procedimientos singulares que permitan revertir dichos procesos de una forma más ordenada, unos mecanismos que sin duda también podrían proyectarse para dar soluciones a la necesaria adaptación del planeamiento al cambio climático.

En el caso andaluz, de una forma muy tímida, el nuevo redactado del artículo 183.3 de la Ley $7 / 2002$, de 17 de diciembre, de ordenación urbanística de Andalucía, regula la utilización de este mecanismo para las parcelaciones ilegales en suelo no urbanizable. Dispone que se deberá llevar a cabo una reagrupación de las parcelas mediante una reparcelación forzosa y en los términos que se determine reglamentariamente.

En el caso valenciano, la existencia, como consecuencia de la crisis, de multitud de planeamiento derivado - programas de actuación integrada - con la ejecución paralizada y sin perspectivas de culminación, planteó la necesidad de buscar soluciones. En este contexto, la nueva Ley 1/2019, de 5 de febrero, de la Generalitat, de modificación de la Ley $5 / 2014$, de 25 de julio, ${ }^{46}$ de ordenación del territorio, urbanismo y paisaje de la Comunidad Valenciana, articula mecanismos para revertir los terrenos al estado, físico, jurídico y urbanístico inicial, lo que

${ }^{46}$ Publicada en el Diari Oficial de la Generalitat Valenciana, núm. 8481, de 7 de febrero de 2019. 
conlleva intervenir no solo físicamente sobre el espacio transformado, sino también jurídicamente en el Registro de la Propiedad.

El nuevo mecanismo, que es definido como la reversión de la reparcelación, habilita diferentes opciones a la administración en función de los diversos escenarios en que se puede encontrar el suelo. Así, obliga a la administración urbanística a desclasificar el suelo urbanizable, devolviéndolo a no urbanizable, si no existe reparcelación y los terrenos no son necesarios para atender a la demanda. En el supuesto de que no existan reparcelación ni obras de urbanización iniciadas, la administración urbanística puede optar entre una nueva clasificación de los terrenos -que puede comportar su desclasificacióno la finalización de las obras de urbanización en unos plazos máximos que varían en función del porcentaje de obras ejecutadas.

Cabe destacar que el mecanismo también incorpora un procedimiento de reversión de la reparcelación mediante un proyecto de reparcelación forzosa. En el proyecto se considerarán como fincas de origen las de resultado de la reparcelación, y como fincas de resultado las que se adjudiquen en el proyecto de reversión. El proyecto no distingue entre propietarios originarios o terceros adquirentes pues, como recuerda el artículo 27.1 del TRLSRU, la transmisión de fincas no modifica la situación del titular respecto de los deberes del propietario y de los establecidos por la legislación de la ordenación territorial y urbanística. La regulación dispone que, en relación a titularidades y derechos y gravámenes inscritos en las fincas de origen, se aplicarán las reglas previstas en la legislación estatal, y también que el proyecto de reversión contendrá, cuando sea necesario, una cuenta de liquidación con las posibles compensaciones económicas resultantes de la devolución de cantidades abonadas o percibidas durante la reparcelación.

Finalmente, en el caso de Catalunya, el Anteproyecto de Ley de territorio ${ }^{47}-$ una ambiciosa reforma de la legislación urbanística, de ordenación del territorio y del paisaje - también contempla un procedimiento de reversión de la

\footnotetext{
47 La documentación del Anteproyecto se puede consultar en el enlace https://goo.gl/YcPvyX (última consulta, 24 de mayo de 2018) y sobre el mismo se puede leer a Josep M. AGUIRRE I FONT, Avantprojecte de la Llei de territori. Document comprensiu, Generalitat de Catalunya, 2017.
} 
parcelación que lleva por nombre "redistribución forzosa de parcelas". Igual que en los casos anteriores, la redistribución forzosa se refiere a las operaciones jurídicas necesarias para restituir la formación de fincas afectadas por un proyecto de distribución urbanística a la situación registral anterior a su inscripción en el Registro de la Propiedad —cuando se desclasifiquen los terrenos o para restituir una segregación de fincas constitutiva de una parcelación urbanística ilegal.

También en este caso se parte de un proyecto que tiene como finalidad la agrupación de las fincas comprendidas en el ámbito de un proyecto de distribución urbanística o de una parcelación urbanística ilegal y su división de conformidad con la situación registral anterior a la inscripción del proyecto de distribución urbanística o de la segregación de fincas.

Destaca en la regulación del proyecto, a diferencia de la regulación valenciana o andaluza, una previsión jurídica en relación a la traslación a las fincas restituidas de las cargas inscritas sobre las parcelas resultantes o segregadas ilegalmente que sean compatibles — un tema nuclear para garantizar la viabilidad de la operación-. Sobre este extremo, el proyecto propone la cancelación o la conversión en un derecho de crédito garantizado, en su caso, con hipoteca, de los derechos o las cargas incompatibles con las fincas restituidas, según acuerden los titulares activos y pasivos del derecho o carga. El proyecto dispone, sin embargo, que la posible falta de acuerdo entre los afectados no impide la aprobación e inscripción del proyecto de redistribución forzosa, si bien, en caso de litigiosidad sobre la valoración, debe inscribirse en el Registro de la Propiedad la anotación preventiva de la demanda correspondiente.

En las tres regulaciones -una de ellas en tramitación y susceptible de modificación - se derivan los conflictos a la esfera patrimonial privada, que deberá resolverlos, y deja a la administración únicamente el papel de impulsar el procedimiento, pero sin ninguna otra carga que devolver las eventuales cesiones efectuadas por los propietarios originarios. Una nueva regulación que demuestra, en cualquier caso, la existencia de instrumentos urbanísticos que permiten revertir situaciones transformadas — con independencia del grado de 
transformación o de la eventual responsabilidad patrimonial que pudiera operar como consecuencia de ello.

\section{CONCLUSIONES}

Un escenario cambiante e imprevisible, consecuencia del cambio climático, exige soluciones adaptativas e innovadoras que permitan limitar de forma efectiva los riesgos derivados del mismo sin recurrir a fórmulas inasumibles económicamente.

En este contexto, el urbanismo juega un papel clave, pues puede limitar usos y aprovechamientos en los espacios en riesgo y tiene capacidad para anticipar escenarios y ofrecer soluciones factibles para los futuros riesgos que sean vinculantes para administraciones y particulares.

Como se ha puesto de manifiesto en este trabajo, el principal reto del planeamiento no es en relación a los nuevos crecimientos, donde las soluciones pasan por planificar adecuadamente a partir de los riesgos conocidos y previsibles, sino en relación a la planificación de los espacios ya transformados o planificados. Sobre estos últimos se impone ahora un cambio de paradigma, pues progresivamente la nueva legislación sectorial en materia de cambio climático o de evaluación ambiental exige al planificador la obligación de incorporar medidas para mitigar y adaptarse al cambio climático.

Las experiencias urbanísticas previas analizadas en este artículo identifican problemas en relación a la intervención en los espacios ya transformados, afectados por riesgos naturales sobrevenidos. La utilización impropia de los espacios libres para mitigar el riesgo, la falta de instrumentos específicos para intervenir en el suelo transformado o la articulación de soluciones mediante indemnizaciones, donde la administración asume la totalidad de los costes, son algunos de ellos.

Por otra parte, los instrumentos de adaptación de la costa al cambio climático de España, Portugal y Francia ofrecen un buen muestrario de ejemplos -fácilmente incorporables a la legislación urbanística- que abordan la adaptación de la costa al cambio climático desde la triple perspectiva de protección, acomodación 
y retroceso, unas herramientas que, en muchos casos, requieren de importantes recursos públicos para hacerse realmente efectivas.

Aun así, en nuestro país, a día de hoy, la gestión del riesgo a partir de la íntegra imputación de los costes a la esfera pública es una solución excepcional de imposible aplicación general a todos los espacios donde aparezcan riesgos naturales sobrevenidos como consecuencia de los cambios en el clima. Ello conlleva necesariamente que la gestión del coste del riesgo deba articularse mediante instrumentos que no conlleven a priori indemnizaciones públicas, lo que con carácter general permite modificar el planeamiento, pero no en cambio expropiar o adquirir los derechos patrimonializados en los espacios en riesgo.

En los espacios transformados, una posible solución pasaría por la configuración de mecanismos donde el planeamiento pudiera progresivamente ir adaptando los usos y obras admitidos en función de la materialización del riesgo. Alternativamente, también se podría plantear resituar el aprovechamiento de un espacio en riesgo mediante alguna actuación que permita redistribuir beneficios y cargas. $O$ incluso obligar a sus propietarios a la reversión de los suelos transformados, total o parcialmente, a la situación original de suelo rústico. Todo ello sin perjuicio de adaptar también la legislación básica estatal, matizando la responsabilidad patrimonial por modificación de planeamiento o singularizando la legislación inmobiliaria en supuestos de riesgo colectivo derivados del cambio climático.

Esas nuevas herramientas no requerirían de grandes cambios en nuestra legislación, que ya contempla en algunos casos mecanismos para transferir aprovechamientos o revertir espacios transformados. Ahora bien, es necesario que estos mecanismos se articulen a una escala supralocal, mediante nuevos planeamientos dinámicos que garanticen la eficacia de sus previsiones y eviten incorporar nuevas cargas al rígido planeamiento local. No se trata solo de establecer limitaciones en los nuevos desarrollos, como hasta ahora, sino de poder intervenir de una manera eficaz ante la imprevisible aparición de nuevos riesgos derivados de la alteración del clima. Debemos avanzar hacia un nuevo modelo urbanístico resiliente al cambio climático, mucho más dinámico que el actual, con capacidad adaptativa y con limitaciones en la patrimonialización de 
los derechos por la aparición de nuevos riesgos. Se trata, en definitiva, de una nueva relación entre el derecho de propiedad y los instrumentos de planeamiento. Un gran reto colectivo. ${ }^{48}$

\section{BIBLIOGRAFÍA}

AgUIRRE I FONT, Josep M., El régimen jurídico del litoral catalán, Atelier, Barcelona, 2014.

Aguirre I Font, Josep M., Avantprojecte de la Llei de territori. Document comprensiu, Generalitat de Catalunya, 2017.

Alli Aranguren, Juan-Cruz y Alli TurRillas, Juan-Cruz, Estudio sistemático del Texto refundido de la Ley del suelo. Real decreto legislativo 2/2008, de 20 de junio, Instituto Navarro de Administración Pública, Dykinson, Madrid, 2008.

Alonso IBÁÑEZ, María Rosario, Retos del desarrollo urbano sostenible e integrado, Tirant lo Blanch, Valencia, 2018

Arellano Ramos, Blanca y Roca Cladera, Josep, Planificación Urbana y Cambio Climático, XLI Reunión de Estudios Regionales, Universitat Rovira i Virgili, Tarragona, 2015.

BASSOLS COMA, Martín, "La ejecución del planeamiento y el cambio climático", Políticas locales de clima y energía: teoría y práctica, Instituto Nacional de Administración Pública, Madrid, 2018.

Baño León, José María, en la obra Derecho urbanístico común, lustel, Madrid, 2009.

Bensusan MaRTín, $\mathrm{M}^{a}$ del Pilar, "Planificación como instrumento de prevención y gestión de los riesgos y desastres naturales" en la obra colectiva Retos del desarrollo urbano sostenible e integrado dirigida por María Rosario ALONSO IBÁÑEZ, Tirant lo Blanch, 2018.

BLASCO ESTEVE, Avelino, "La planificación territorial como factor decisivo del desarrollo territorial sostenible" en la obra colectiva Retos del desarrollo urbano sostenible e integrado dirigida por María Rosario ALONSO IBÁÑEZ, Tirant lo Blanch, 2018.

BUSTILLO BOLADO, Roberto O., "Integración y eficiencia de los recursos naturales en el ecosistema urbano" en la obra colectiva Retos del desarrollo urbano

\footnotetext{
48 Las implicaciones sobre el cambio climático y el derecho de la propiedad son de escala global, como ponen de manifiesto Mark FREUdenBerger y David MiLleR en Climate Change, Property Rights, \& Resource Governance. Emerging Implications for USG Policies and Programming, U.S. Agency for International Development or the U.S. Government, 2010. También la obra de Fennie VAN StRAalen, Thomas HARTMANn y John SheEHAN titulada Property Rights and Climate Change: Land use under changing environmental conditions, Routledge, Londres, 2018.
} 
sostenible e integrado dirigida por María Rosario ALONSO IBÁÑEZ, Tirant lo Blanch, 2018.

CARBonell, Armando, Zogran, Martin y SiJmons, Dirk, "Cambio climático, agua, urbanización de terrenos y adaptación: planificar desde la incertidumbre (Almare, Países Bajos)", en Urbanismo ecológico, Harvard University, Graduate School of Design, Editorial GG, Barcelona 2014.

CUYÁs PALAZÓN, Ma Mercedes, "Los retos de la planificación estratégica" en la obra colectiva Retos del desarrollo urbano sostenible e integrado dirigida por María Rosario ALONSO IBÁÑEZ, Tirant lo Blanch, 2018.

De La SALA, Safira "Considerações acerca da Política de Mudança do Clima no Município de São Paulo Lei no 14.933 de 5 de Junho de 2009", Revista Brasileira de Ciências Ambientais, núm. 30, Rio de Janeiro, 2013.

Delgado-JIMÉnez, Alexandra, "El impacto de las políticas climáticas en la legislación urbanística: una nueva agenda en relación con los usos del suelo y la energía", Políticas locales de clima y energía: teoría y práctica, Instituto Nacional de Administración Pública, Madrid, 2018

DOMĖNECH BeRENGUER, Cristina, "Transformació urbana del barri de l'estació (Sallent)", Anuari Territorial de Catalunya, Societat Catalana d'Ordenació del Territori, Institut d'Estudis Catalans, Barcelona, 2005.

ESTEBAN I Noguera, Juli, L'ordenació urbanística: conceptes, eines i practiques, Col-lecció Estudis, Diputació de Barcelona, 2007 (2ª edición).

FLINT, Anthony, "Los derechos de propiedad y el cambio climático", Land Lines Magazine, Lincoln Institute of Land Policy, Cambridge, 2013.

FRANCIA ACUÑA, Laura I., a "Las transferencias de aprovechamiento urbanístico como mecanismo de gestión para la obtención gratuita de suelos dotacionales y para compensar déficits de áreas verdes", Revista de derecho urbanístico y medio ambiente, núm. 297, Madrid, 2015.

Freudenberger, Mark y Miller, David, Climate Change, Property Rights, \& Resource Governance. Emerging Implications For USG Policies And Programming, U.S. Agency for International Development or the U.S. Government, Washington, D.C., 2010.

Gardner, Gary; Prugh, Tom y Renner, Michael, Ciudades Sostenibles. Del sueño a la acción. La situación del Mundo 2016, Icaria Editorial, Barcelona, 2016.

GIFREU FONT, Judith, "La protección y utilización del demanio marítimo-terrestre a propósito de la reciente jurisprudencia constitucional. Hacia una ordenación integrada y sostenible del litoral de Cataluña", Práctica Urbanística, núm. 140, Editorial Wolters Kluwer, 2016. 
GonzÁlez Pérez, Jesús, Comentarios a la Ley del suelo. Volumen II, ThomsonCivitas, Pamplona, 2015 ( $3^{\text {a }}$ edición).

Hartmann, Thomas, van Straalen, Fennie y Sheehan, John, Property Rights and Climate Change: Land use under changing environmental conditions, Routledge, London, 2018.

INARAJA VerA, Luis titulado "Ciudades y lucha contra el cambio climático: experiencias de municipios estadounidenses", Cuadernos de Derecho Local, núm. 56, Fundación Democracia y Gobierno Local, Barcelona, 2018.

LLEAL GraU, Mariona, "La responsabilidad patrimonial de la Administración Pública por alteración de la ordenación territorial y urbanística", Revista de urbanismo y edificación, núm. 19, 2009, Aranzadi, Navarra, 2010.

LÓPEZ PÉREZ, Fernando, "La planificación urbanística municipal ante el cambio climático: expansión versus ciudad existente", Políticas locales de clima y energía: teoría y práctica, Instituto Nacional de Administración Pública, Madrid, 2018.

MAXANT, Jean-René, "La résilience des écosystèmes comme concept de gestion du littoral: les défis communs du traitement juridique des constructions et activités en zone à risques", Revista de Investigación Marina, núm. 25.2, Pasaia, 2018.

MENÉNDEZ REXACH, Ángel Planificación y gestión del agua ante el cambio climático: experiencias comparadas y el caso de Madrid, La Ley, Madrid, 2012.

MENÉNDEZ Sebastián, Eva, Los supuestos indemnizatorios en la Ley 8/2007 de suelo y en la legislación sobre espacios naturales, Thomson-Aranzadi, Navarra, 2007.

MUSTAFÁ TOMÁs, Yásser-Harbi, "Régimen de las transferencias y reservas de aprovechamiento urbanístico. En especial, el régimen de la Comunidad Valenciana", Revista de derecho urbanístico y medio ambiente, núm. 252, Madrid, 2009.

Noguera de LA Muela, Belén, "La protecció del litoral a propòsit de la llei de protecció i ús sostenible del litoral de 2013 i el reglament de desenvolupament de 2014" a El desenvolupament e l'autogovern en matèria de territori, paisatge, litoral $i$ urbanisme, coordinada por Joan Manuel TRAYTER JIMÉNEZ y Carles GaRCía RocASALVA, Institut d'Estudis Autonòmics, Barcelona, 2017.

Pedro Costa, João, Urbanismo e Adaptação às Alterações Climáticas. As frentes de agua, Livros Horizonte, Lisboa, 2013.

Pons CÁnovas, Ferran, El nuevo régimen jurídico de las costas, ThomsonReuters Aranzadi, Navarra, 2015. 
Pons CÁnOVAS, Ferran, "Resiliencia de la costa a los impactos del cambio climático después de la reforma de la normativa costera", Revista de derecho urbanístico y medio ambiente, núm. 329, 2019.

SANZ LARRUGA, Francisco-Javier, "Costas y litoral: biodiversidad marina, cambio climático y otras cuestiones" en Observatorio de Políticas Ambientales 2016, coordinado por Fernando LÓPEZ RAMÓN, CIEMAT, Madrid, 2016.

SANZ LaRRUGA, Francisco-Javier, "Cambio climático y zonas costeras: aproximación a su ordenación jurídica y el papel de las administraciones locales", Políticas locales de clima y energía: teoría y práctica, Instituto Nacional de Administración Pública, Madrid, 2018

Simou, Sofía, "La configuración filoclimática del derecho de propiedad", InDret, Revista para análisis del derecho, núm. 3, Barcelona, 2017.

Tapan K DHAR y Luna KHIRFAN, "Climate change adaptation in the urban planning and design research: missing links and research agenda", Journal of Environmental Planning and Management, vol. 60, núm.4, Newcastle, 2017

Trayter Jiménez, Joan, Derecho Urbanístico de Cataluña, Atelier, Barcelona, 2016 (6ª edición).

VAlLeSPINós, Ferran y CucuRULL, Domènec, Mitigación y adaptación local al cambio climático, Diputació de Barcelona, Barcelona, 2008.

Verdaguer Viana-CÁrdenas, Carlos (Dir), Medidas para la mitigación y la adaptación al cambio climático en el planeamiento urbano. Guía metodológica, Federación Española de Municipios y Provincias, Madrid, 2015. 